\title{
TU/e EmonONEN

\section{A systematic literature review of studies on business process modeling quality}

\section{Citation for published version (APA):}

Moreno-Montes de Oca, I., Snoeck, M., Reijers, H. A., \& Rodríguez-Morffi, A. (2015). A systematic literature review of studies on business process modeling quality. Information and Software Technology, 58, 187-205. https://doi.org/10.1016/j.infsof.2014.07.011

DOI:

10.1016/j.infsof.2014.07.011

Document status and date:

Published: 01/01/2015

\section{Document Version:}

Publisher's PDF, also known as Version of Record (includes final page, issue and volume numbers)

\section{Please check the document version of this publication:}

- A submitted manuscript is the version of the article upon submission and before peer-review. There can be important differences between the submitted version and the official published version of record. People interested in the research are advised to contact the author for the final version of the publication, or visit the $\mathrm{DOI}$ to the publisher's website.

- The final author version and the galley proof are versions of the publication after peer review.

- The final published version features the final layout of the paper including the volume, issue and page numbers.

Link to publication

\section{General rights}

Copyright and moral rights for the publications made accessible in the public portal are retained by the authors and/or other copyright owners and it is a condition of accessing publications that users recognise and abide by the legal requirements associated with these rights.

- Users may download and print one copy of any publication from the public portal for the purpose of private study or research.

- You may not further distribute the material or use it for any profit-making activity or commercial gain

- You may freely distribute the URL identifying the publication in the public portal.

If the publication is distributed under the terms of Article 25fa of the Dutch Copyright Act, indicated by the "Taverne" license above, please follow below link for the End User Agreement:

www.tue.nl/taverne

Take down policy

If you believe that this document breaches copyright please contact us at:

openaccess@tue.nl

providing details and we will investigate your claim. 


\title{
A systematic literature review of studies on business process modeling quality
}

\author{
Isel Moreno-Montes de Oca ${ }^{\mathrm{a}, *}$, Monique Snoeck $^{\mathrm{b}}$, Hajo A. Reijers ${ }^{\mathrm{c}}$, Abel Rodríguez-Morffi ${ }^{\mathrm{a}}$ \\ a Faculty of Mathematics, Physics and Computer Science, Central University "Marta Abreu" of Las Villas (UCLV), Carretera a Camajuaní km 5 1/2, Santa Clara, VC, Cuba \\ ${ }^{\mathrm{b}}$ Faculty of Business and Economics, Catholic University of Leuven (KU Leuven), Naamsestraat 63, 3000 Leuven, Belgium \\ ${ }^{\mathrm{c}}$ Department of Mathematics and Computer Science, Eindhoven University of Technology (TU/e), The Netherlands
}

\section{A R T I C L E I N F O}

\section{Article history:}

Received 25 March 2014

Received in revised form 11 June 2014

Accepted 21 July 2014

Available online 30 July 2014

\section{Keywords:}

Systematic literature review

Business process modeling

Modeling quality

\begin{abstract}
A B S T R A C T
Context: Business process modeling is an essential part of understanding and redesigning the activities that a typical enterprise uses to achieve its business goals. The quality of a business process model has a significant impact on the development of any enterprise and IT support for that process.

Objective: Since the insights on what constitutes modeling quality are constantly evolving, it is unclear whether research on business process modeling quality already covers all major aspects of modeling quality. Therefore, the objective of this research is to determine the state of the art on business process modeling quality: What aspects of process modeling quality have been addressed until now and which gaps remain to be covered?

Method: We performed a systematic literature review of peer reviewed articles as published between 2000 and August 2013 on business process modeling quality. To analyze the contributions of the papers we use the Formal Concept Analysis technique.

Results: We found 72 studies addressing quality aspects of business process models. These studies were classified into different dimensions: addressed model quality type, research goal, research method, and type of research result. Our findings suggest that there is no generally accepted framework of model quality types. Most research focuses on empirical and pragmatic quality aspects, specifically with respect to improving the understandability or readability of models. Among the various research methods, experimentation is the most popular one. The results from published research most often take the form of intangible knowledge.

Conclusion: We believe there is a lack of an encompassing and generally accepted definition of business process modeling quality. This evidences the need for the development of a broader quality framework capable of dealing with the different aspects of business process modeling quality. Different dimensions of business process quality and of the process of modeling still require further research.
\end{abstract}

(c) 2014 Elsevier B.V. All rights reserved.

\section{Contents}

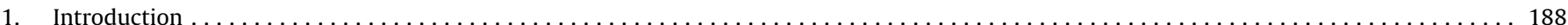

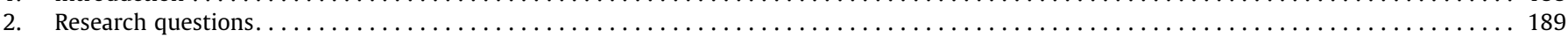

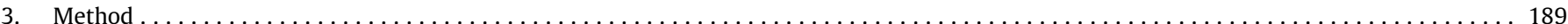

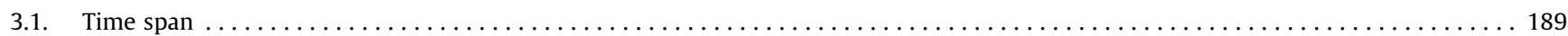

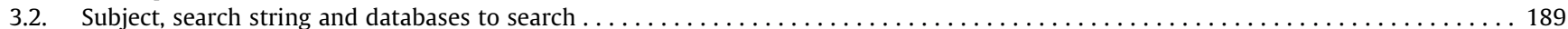

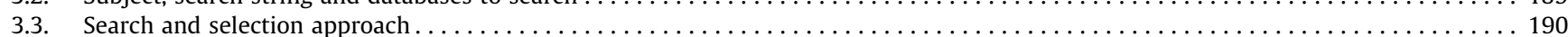

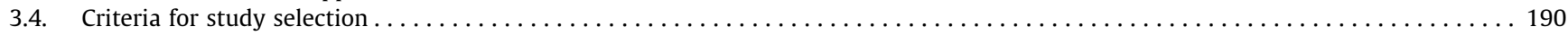

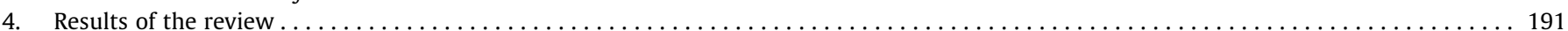

\footnotetext{
* Corresponding author.

E-mail addresses: Isel@uclv.edu.cu (I. Moreno-Montes de Oca), Monique. Snoeck@kuleuven.be (M. Snoeck),H.A.Reijers@tue.nl (H.A. Reijers), ARM@uclv. edu.cu (A. Rodríguez-Morffi).
} 


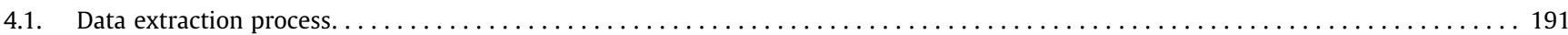

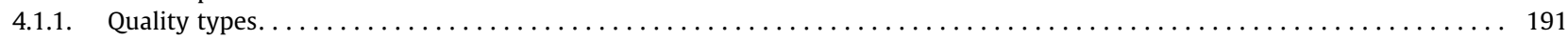

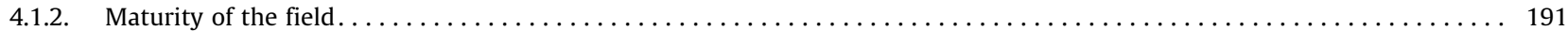

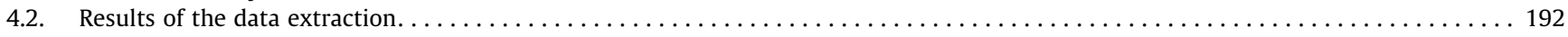

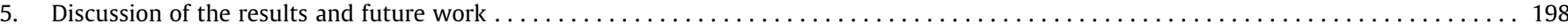

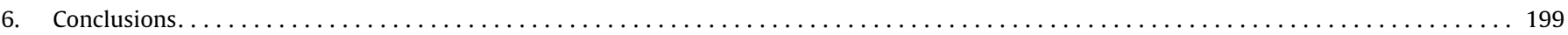

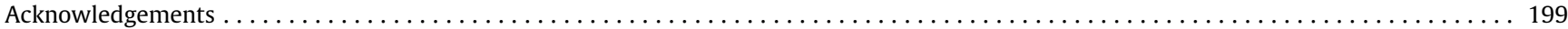

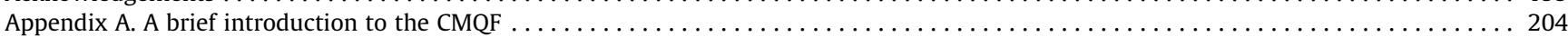

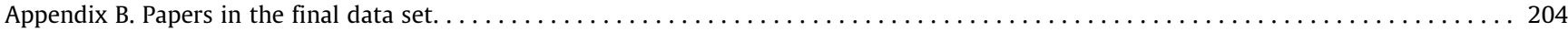

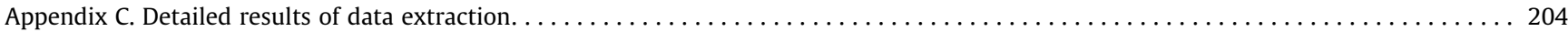

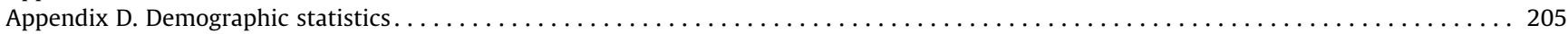

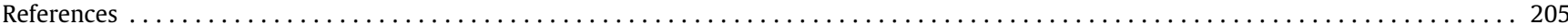

\section{Introduction}

Business process modeling is arguably one of the important domains of interest of information systems research over the past three decades. From an Enterprise Modeling perspective, business process modeling is valued as a complement to domain modeling. It allows capturing the organizational dimension in terms of actors, activities, and workflows. Business process models (or process models for short) are required as a basis for knowledge transfer, quality purposes, regulations, communication between internal and external collaborative partners, and documentation in general [1]. Business process models also play an important role in the requirements engineering process of software systems development. As-is models help to understand the work that needs to be supported by information systems. Designing high quality to-be business process models is a prerequisite for leveraging the benefits of process improvement and it is crucial for the design of information systems [2]. Good process model design can help to avoid errors right from the start. This is vital, since the cost of errors increases exponentially over the development lifecycle [3]. All of these factors explain why quality assurance of business process models has been recognized as an important factor for modeling success at an enterprise level over the past years. Therefore, business process modeling is an essential part of understanding and redesigning the activities a typical enterprise uses to achieve its business goals. Moreover, the quality of business process models will impact on the quality of (the design of) information systems and on envisaged business process improvements.

Business process models are not always of high quality. Various studies have shown that many business process models contain errors, such as syntactical mistakes (for an overview see [4]). There is clearly a need to offer guidelines to practitioners on how models of high quality are to be created $[5,6]$.

Several research works on business process modeling quality have contributed to the evolution of the knowledge in this area. At the same time, research on conceptual modeling (CM) quality has evolved. An example of this evolution is the successive creation of quality frameworks [5,7-10] with an increasing number of quality dimensions. Since process models can also be seen as conceptual models these two research areas are very close. Nonetheless, only a small amount of research works have contributed to the interrelation between business process modeling quality and CM quality frameworks (see for example [11,12]). Besides, early research on business process modeling quality is not always based on recent advances in the understanding of $\mathrm{CM}$ dimensions. Because of this, guidelines for good process models are unorganized and dispersed in different papers (e.g. [5,6,13-18]), and there is no view on how complete this set of guidelines is.

In order to advance the field on modeling quality it is useful to determine its current state of the art by identifying, evaluating and interpreting relevant research to date that is related to business process modeling quality.
A search for literature reviews yielded a number of reviews that have been performed in the business process modeling area. As far as we are aware of, no systematic review on the topic of business process modeling quality has been performed yet. O'Neill and Sohal [19] performed a review on business process reengineering. Biazzo [20] highlighted and compared alternative techniques and approaches for business process analysis. Aguilar Saven [21] reviewed and described the main process modeling techniques. Genero et al. presented a literature review on the quality of UML models [22]. Aldin and de Cesare [23] made a literature review on business process models reusability. Sanchez-Gonzalez et al. [24] analyzed the current state of the art and trends with regard to business process model metrics. They performed a literature review on this subject covering the period from 1998 until 2008. Another summary of related work on metrics can be found in Mendling's book: Metrics for Process Models [25]. None of the above studies provide a clear overview of the state of the art on business process modeling quality.

Given the absence of a literature overview on business process modeling quality, the goal of the research presented here is to perform a systematic literature review (SLR) of papers dealing with business process modeling quality based on the original SLR guidelines as proposed by Kitchenham in [26]. In particular, the goal of this SLR is to provide an inventory of "what has been done" in previous years in the context of quality guidelines for business process modeling. We thus focus on (i) papers that aim to evaluate or improve the business process models quality as a product by proposing practical modeling artifacts (i.e. quality metrics, pragmatic guidelines) and (ii) papers that contribute to the improvement of business process modeling as a process (i.e. enhanced methods for the process of business process modeling). In an attempt to bring about a closer alignment between business process modeling quality and $\mathrm{CM}$ quality, we will use a CM quality framework for the interpretation of quality concepts addressed by business process modeling quality papers (i.e. types of quality issues addressed by researchers).

An SLR involves three main activities: planning the review, conducting the review, and reporting the review [26]. Each activity has several stages associated to it. Planning the review includes the specification of the research questions and the development of the review protocol. Conducting the review includes study selection, data extraction, and data synthesis. Finally, the stages associated with reporting the review are mainly concerned with the presentation and interpretation of the results. As Da Silva [27] pointed out, some of the above mentioned activities in an SLR require decisions about possibly conflicting situations. Each disagreement in this SLR was resolved by seeking a consensus between all four researchers. Particularly, for the study selection and the reliability of inclusion decisions, one author of the paper made a list of included/excluded papers from the initial set of papers that resulted from the systematic search process (see below). Subsequently, the list of included and excluded papers was discussed with the three other authors. 
The rest of the paper is structured as follows. Section 2 presents the research questions that will drive the entire systematic review methodology. Section 3 discusses the strategy used to search for primary studies and the study selection criteria. Section 4 presents the extracted data of our SLR. Section 5 presents an analysis of the findings and directions for future research. Finally, Section 6 presents conclusions.

\section{Research questions}

Since research questions guide the design of the review process, specifying them is the most important part of any systematic review [26]. In view of the systematic literature the research questions are formulated as follows:

RQ1: Which types of quality issues are being addressed by researchers and how are the studies distributed across these issues?

As current guidelines and knowledge on business process modeling quality is dispersed across many papers, the quality dimensions identified in $\mathrm{CM}$ quality frameworks will be used as a way to structure the analysis of the body of knowledge on business process modeling quality. This will enable to determine which issues get the most/least attention from the business process modeling research community, and to assess the completeness of the current body of knowledge.

RQ2: How mature is the business process modeling research field?

In the literature we find guidelines that are based on scientific research (see for example $[6,16]$ ). However, as indicated in [6], there are also collections of pragmatic hints that lack a sound foundation. Therefore, the aim of this second research question is to assess the current maturity of business process modeling quality research. Given the absence of a widely accepted definition of research maturity, we mainly rely on the categorization along three dimensions used in [22]. First, research goals are an indication of the knowledge that is aimed for. Next, research may also be supported by different kinds of research methods and ensuing levels of evidence these support. Finally, given the wide area of research on business process modeling quality, many different means can be envisaged to contribute to modeling quality and hence research may yield different types of results. An analysis along this dimension allows us to organize the body of knowledge in terms of the type of results. Therefore, the following subquestions refine RQ2:

(a) What are the business process modeling quality research goals? Examples of quality goals are: understanding, measuring, evaluating, assuring and improving. An analysis along this dimension allows determining where most/least of the research interest lies.

(b) Which research methods are more/less used in the research area? Example research methods are: argumentation, scenario's to demonstrate the utility of some research result or artifact, experiment, case study, field study, and survey. The analysis along this dimension will allow to assess the maturity of research results for each of the dimensions identified above, in terms of their fundamental or applied research nature and the level of scientific validation of the proposed results.

(c) Which type of research results are provided on business process modeling quality research works? In IS research, results can be categorized [28] as constructs (conceptualizations), models, methods and artifacts. For the domain of business process modeling quality, example types of research results are knowledge, metrics, quality models, methods, checklists, guidelines, notations, and modeling conventions.

\section{Method}

Aside from the research questions that steer the SLR, establishing a good search strategy also requires the answering of a number of additional questions [29]:

1. What time span is to be considered?

2. What subject (evidence type) is to be searched, and what are queries (search strings) fed into which search engines or sources?

3. Which approach is to be used in search process (e.g., manual or automated search)?

4. Which criteria are to be used for the selection of studies?

These questions are respectively answered in the following sections.

\subsection{Time span}

We performed our search for the studies on business process modeling quality over the timespan of November 2012 to August 2013. As stated in $[3,16]$, process modeling has been around for some 30 years; however, only more recently research has started to examine quality aspects pertaining to process modeling. According to a trend analysis on publications on "business process modeling" in the Web of Science (WoS), the earliest publication on this topic dates from 1987. Subsequently, a slight increase in publications can be witnessed between 1994 and 2001, with a significant increase starting in 2002. Likewise, citations start to boom in 2003. According to a trend analysis in Google Scholar, we see publication numbers increasing with $50 \%$ per year, starting in 2000 . We therefore consider a period of time starting in 2000, relying on the assumptions that by omitting the period before 2000, we will omit only a minor fragment of potentially relevant research. This assumption was verified by looking at the data collection from the literature review on the quality of UML models [22]: although the Lindland, Sindre and Sølvberg framework on conceptual modeling quality was published in 1994 [7], only 5 out of the 266 papers date from before 2000. Similarly, in [24] an SLR is performed on business process metrics, covering the period from 1998 until 2008. The oldest paper reported on is from 2001. Furthermore, we assume that topics researched in the pre-2000 period have been further investigated after 2000 .

\subsection{Subject, search string and databases to search}

The main area of research within which relevant papers may be found determines the main search terms as well: "business process modeling" and "quality". Given the fact that the aim of the research is to identify the different types of quality addressed by current research on business process modeling, a number of alternative terms for "quality" need to be considered. Therefore, for the construction of the search string we identified alternative spellings, synonyms and related terms as suggested in [30]. After that, we filtered several strings in ISI WoS and scanned the results to check their quality and the inclusion of well-known relevant literature.

As a final check, the search string was updated and re-run in order to reflect frequently occurring words in the titles of relevant papers found through reference search results. This yielded the following, final search string: 


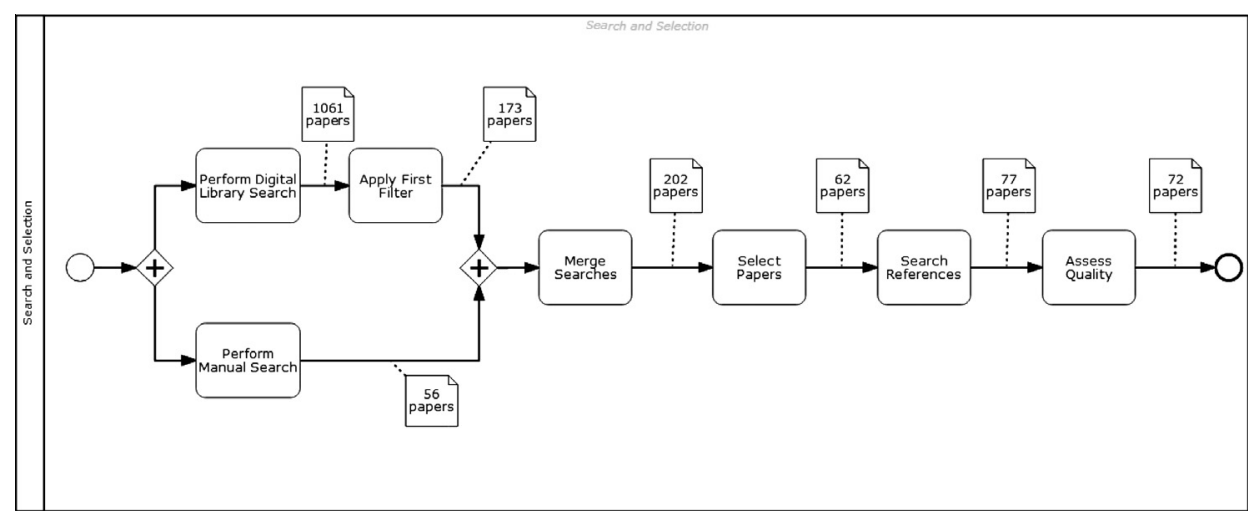

Fig. 1. Identification of included studies.

Title $=\left(\right.$ "quality" OR eval" OR consistenc ${ }^{*}$ OR "maintainability" OR understand" OR "completeness" OR comprehensi" OR "testability" OR defect ${ }^{*}$ OR pitfall ${ }^{*}$ OR deficienc ${ }^{*}$ OR error ${ }^{*}$ OR mistake* OR problem* OR "effectiveness" OR "complexity" OR "readability" OR metric ${ }^{*}$ OR measur ${ }^{*}$ OR efficienc ${ }^{*}$ OR validat OR layout" OR guideline* OR "flexibility" OR "recommendation" OR correctn") AND Title $=\left(\right.$ "process") AND Title $=\left(\right.$ modell ${ }^{*}$ OR representation ${ }^{*}$ OR diagram*)

Refined by: Research Areas $=($ COMPUTER SCIENCE OR BUSINESS ECONOMICS) AND Document Types $=($ MEETING OR ARTICLE $)$

Timespan = 2000-2013.

Search language $=$ Auto .

By including meetings as document type, we ensured that conference papers were included in the search as well. Major conferences in the domain publish their proceedings through Springer, IEEE, ACM or other publishers that have their publications indexed in the WoS. By including computer science and business economics as subject areas we made sure that research published in outlets from computer science and business are included.

\subsection{Search and selection approach}

Given the broad nature of the domain of research, finding all relevant papers by manually searching through conferences and journals would be very time consuming. We therefore opted to start the search process with an automated search. We subsequently completed the set of papers through (1) a manual search by scanning conferences proceedings, DBLP and personal pages of several well-known authors in the business process modeling quality research area, and (2) a reference search. We limited the search to electronic collections only and solely considered journals, conference proceedings, and workshop proceedings that were peer reviewed. Fig. 1 shows a full overview of the search process.

The collection of 1061 papers obtained by the automated search was reduced by applying a first filter on title and abstract, resulting in a set of 173 papers. As a result of the manual search process we obtained an additional set of 56 potentially relevant research papers. 29 of these papers were not included in the results of the automated search. 15 papers out of these 29 papers are not included in the WoS and could indeed never have been identified through the automated search.

After bringing together the papers returned by the automated search and those obtained by the manual search, we applied the selection criteria on the full papers. This yielded 62 papers to be included in the final paper set. For the references search, we read these 62 papers in detail and investigated their references in search for more relevant papers. This references search yielded 69 potentially relevant papers. After a detailed reading of these papers, the inclusion/exclusion criteria were also applied to them. This resulted in 15 papers to include. Finally, we merged the two sets. At the end of this stage, we obtained 77 studies. Of these 77 studies 2 were excluded for being considered duplicate publications of the same results (i.e. [31] for paper 6 and [32] for paper 24 in Appendix B). For duplicate studies we kept the most complete and recent publication as recommended by [26,33]. Also, we excluded 3 more papers for not being published in peer reviewed conference proceedings or journals. This yields 72 papers as final set for the SLR.

At the end of the search process, we checked the quality of the search string that yielded the initial set of 1061 papers. This was done by checking whether all the papers of the most frequently occurring author appeared in the list, and, if not, whether there is a logical explanation for this. According to the WoS search engine, J. Mendling is the author with the highest number of publications in the set of 1061 papers. At the end of the search process, he appeared as (co-)author of 28 out of the final set of 72 papers. Therefore, he is both at the start and at the end of the process the most frequently publishing author in this domain. Out of the 28 papers (co-)authored by J. Mendling, 3 are not indexed in the WoS. The automated search yields 20 of the 25 indexed papers, a recall of $80 \%$. The 5 papers that were not found have titles that do not clearly refer to business process model quality keywords, e.g. "Refactoring large process model repositories". We investigated whether the absence of the right keywords in the title could be overcome by searching on topic rather than on title. However, this is not an option as a search on topic rather than on title resulted in more than 200,000 papers.

We are aware that because of the high number of papers published in the domain of business process modeling, it is practically impossible not to miss some sources. Nevertheless, given the high recall for the author with the largest number of publications, we gathered further confidence that the performed automated search in combination with the manual search and the reference search can be considered as sufficiently complete or at least sufficiently representative.

\subsection{Criteria for study selection}

At three places in the search process (after the digital library search, the manual search and the reference search), a selection of the papers was performed by applying inclusion and exclusion criteria to the papers. These criteria were determined as follows. In this SLR we consider business process modeling from a conceptual modeling point of view as part of the process discovery phase [34]. In particular, we are in search of quality guidelines that are independent of the modeling language and the modeling tools. 
Other phases of the business process management cycle such as model analysis, redesign, implementation, monitoring and controlling are out of scope. For that reason, papers that focus on the following aspects were excluded:

- language or tool comparison,

- transformations from one language to another,

- qualities of specific modeling languages,

- tool support,

- algorithms for the formal verification of process models for e.g. deadlock or safety (since such algorithms are typically implemented into tools whereas we target guidelines for practitioners),

- the integration of business processes with information systems or web services,

- business process model execution,

- organizational excellence,

- business process redesign,

- business process reengineering,

- cost optimization,

- business process reference models,

- process mining.

Papers that addressed language issues as part of assessing the quality of a process model were kept in the SLR. About 20 papers that report specifically on the quality of a modeling language (e.g. in terms of BPEL semantics, ontological quality), were excluded.

\section{Results of the review}

\subsection{Data extraction process}

\subsubsection{Quality types}

To answer RQ1 we investigated the types of quality addressed by the papers. We considered two dimensions of quality according to the distinction made in the quality management literature [35]:

- Product quality: This dimension addresses the quality of a business process model as the end product of a modeling exercise. This dimension can be used to classify papers that assess quality along quality types similar to the dimensions of the SEQUAL quality framework [7] or measure process model characteristics in a quantitative way.

- Process quality: This dimension addresses the quality of the modeling process itself. This dimension can be used to classify papers that propose (improved) practices or evaluate practices.

We identified the quality dimensions addressed by the research as named by the authors. Additionally, we registered whether the authors present a precise definition of quality in their studies (e.g. by referring to a quality framework or to a standard for quality). Given the large, overall number of quality attributes mentioned by the authors (about 50 different terms) and the fact that many different names are used for the same attributes or vice versa, we needed to characterize the papers according to a uniform quality framework in order to gain useful insights when answering RQ1.

For this reason, we looked into the successive CM quality frameworks $[7,10]$ as well as existing business process modeling quality frameworks [5,9]. The Conceptual Modeling Quality Framework (CMQF) of Nelson et al. $[7,10]$ seemed to be the better choice to classify papers. First of all, it combines the quality dimensions of SEQUAL and BWW [36]. In this way, the framework is useful for evaluating the end result of the conceptual modeling process, the conceptual representation, and the quality of the modeling process itself as well. In addition, it also contains the quality attributes of SIQ and partially overlaps with GoM. It is therefore the framework with the richest set of product quality dimensions.

The CMQF identifies 24 quality dimensions. Not all of these are relevant for the product quality perspective. A brief explanation of the CMQF can be found in Appendix A. In this appendix we also motivate which quality dimensions from the CMQF were retained for analyzing the papers in answer to RQ1.

\subsubsection{Maturity of the field}

In order to assess the maturity of the field (RQ2), we look into research goals, research methods, and types of results. The classification scheme used to answer these questions are similar to the ones presented in [22].

To assess the Research Goal of the studies we considered five research goals [22]. Understanding refers to papers that seek to define dimensions of quality. Measuring is for papers the research goal focus on the development and evaluation of scales to characterize model quality. Evaluating is for papers that study the relationship between quality measurements and real world experiences with the model. Assurance research examines how to ensure that the process that produces the model actually does produce a high-quality model. Finally improving examines how to increase the current quality of models.

To assess the Research Methods, we considered the research methods from [22] and cross checked it with the list of validation methods proposed in [37]. We used:

- Speculation (called Informed argument in [37]) for proposals which address business process modeling quality without presenting any study or example that would indicate feasibility and validity of the results.

- Example for investigations that are illustrated by an example (this could be real-life or not).

- Literature Review for a review of prior research.

- Experiment for investigations of testable hypotheses where one or more independent variables are manipulated to measure their effect on one or more dependent variables.

- Case Study for empirical inquiries that investigate a contemporary phenomenon within its real-life context, especially when the boundaries between phenomenon and context are not clearly evident.

- Survey for those investigations that perform a research-inthe-large by sending a questionnaire to or interviewing a large number people covering whatever target population is needed.

To assess the type of research result of a paper we classified the research outcome into quality model, notation, method or algorithm, tool, metric, knowledge, pattern, view and guidelines as defined in [22]. A quality model defines a set of characteristics, and of relationships between them, which provides a framework for specifying quality requirements and evaluating quality. A notation is a system of symbolic representations of objects and ideas. A method or algorithm is a finite sequence of instructions used to prevent or detect and delete deficiencies in models. A tool gives automatic support to the evaluation or assurance of quality considering different techniques. A metric is a measurement scale and the method used for assessment. Knowledge refers to other types of results that are not "tangible", for example a confirmation of a theory. A pattern is a type of theme of recurring events or objects, sometimes referred to as elements of a set. A view is a representation of a whole system from the perspective of a related set of concerns. Finally, guidelines refer to explicit best practices for the creation of models. 
Table 1

Relationship between the CMQF quality types and other quality categories.

\begin{tabular}{|c|c|}
\hline CMQF quality types & Categories as mentioned by the authors \\
\hline Syntactic quality & Errors, correctness, syntactic quality \\
\hline Intensional quality & (did not appear in any paper) \\
\hline Semantic quality & Errors, soundness, completeness, correctness, semantic quality \\
\hline Empirical quality & $\begin{array}{l}\text { Errors, readability, maintainability, correctness, structural complexity, structuredness, modularity, } \\
\text { complexity, reusability, model representation factors (labels, icons and layout) quality, } \\
\text { modifiability, connectivity, understandability }\end{array}$ \\
\hline Perceived syntactic quality & $\begin{array}{l}\text { Personal factors relating to modeling experience, educational background, analytical skills, visual } \\
\text { perceptiveness and general user characteristics }\end{array}$ \\
\hline Perceived intensional quality & $\begin{array}{l}\text { Personal factors relating to modeling experience, educational background, analytical skills, visual } \\
\text { perceptiveness and general user characteristics }\end{array}$ \\
\hline Perceived semantic quality & $\begin{array}{l}\text { Perceived ambiguity, perceived usefulness, completeness, personal factors relating to modeling } \\
\text { experience, educational background, analytical skills, visual perceptiveness and general user } \\
\text { characteristics }\end{array}$ \\
\hline Perceived empirical quality & (did not appear in any paper) \\
\hline Pragmatic quality & Understandability, pragmatic quality \\
\hline Applied domain knowledge quality & (did not appear in any paper) \\
\hline Applied model knowledge quality & (did not appear in any paper) \\
\hline Applied language knowledge quality & (did not appear in any paper) \\
\hline
\end{tabular}

Table 2

Sample classification of 10 papers.

\begin{tabular}{lllll}
\hline & QA1 & QA2 & QA3 & QA4 \\
\hline Paper 1 & 1 & 0 & 0 & 0 \\
Paper 2 & 0 & 1 & 0 & 0 \\
Paper 3 & 1 & 1 & 1 & 0 \\
Paper 4 & 0 & 1 & 0 & 1 \\
Paper 5 & 1 & 0 & 0 & 1 \\
Paper 6 & 0 & 0 & 0 & 1 \\
Paper 7 & 0 & 0 & 0 & 1 \\
Paper 8 & 1 & 1 & 1 & 1 \\
Paper 9 & 1 & 0 & 0 & 0 \\
Paper 10 & 1 & 0 & 0 & 0 \\
\hline
\end{tabular}

\subsection{Results of the data extraction}

In this section, for each research question, we provide a summary of the data collected from the 72 papers. A detailed account of the data collected can be found in Appendix B and in Appendix C. Some further demographic information about the papers can be found in Appendix D.

RQ1: Which types of quality issues are being addressed by researchers and how are the studies distributed across these issues?

The quality types as defined by the authors and the CMQF where collected and related as a result of this SLR (see Table 1).
The quality types defined by the authors refer to quality aspects according to what they believe they are addressing. In general, one can say that many different terms are used and that the terms are not always clearly defined. As an example, some authors use the word "correctness" to refer to syntactic quality; sometimes it refers to semantic quality and sometimes to empirical quality. In addition, the quality types of the CMQF seem to capture different aspects into one term. In particular, empirical quality covers a wide domain of quality aspects. This large variety of aspects originates from the many papers dealing with process metrics and the inspiration that is taken from the domain of software metrics. Also, certain specific aspects of business process quality such as soundness, refer to "internal" quality aspects that are not directly addressed by the CMQF. In quality frameworks, semantic quality refers to the meaning of a model, and whether or not the statements of a model are considered to be a correct reflection of the real world. When matching author quality types to the CMQF quality types, the authors first sought clarity on the corresponding CMQF quality dimension by matching the performed research to CMQF definitions. For example, we considered that the "meaning" of an unsound model is in general considered to be incorrect and therefore reflects a semantic quality deficit. In case different quality dimensions could apply (for example for research investigating the effects of personal factors on model understanding), we gave preference to the root quality dimension investigated (model understanding), leaving the moderating factor (personal factors) in the classification along the authors only.

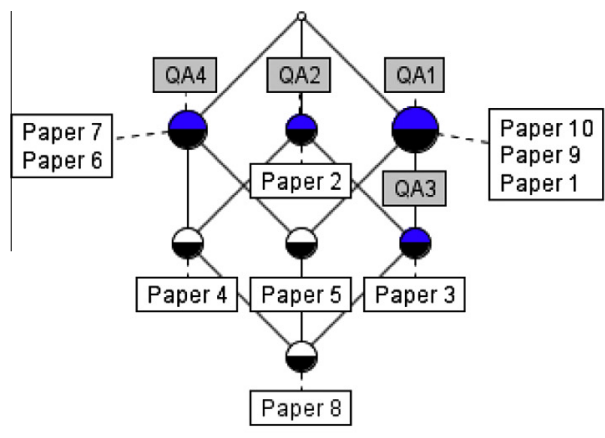

(a)

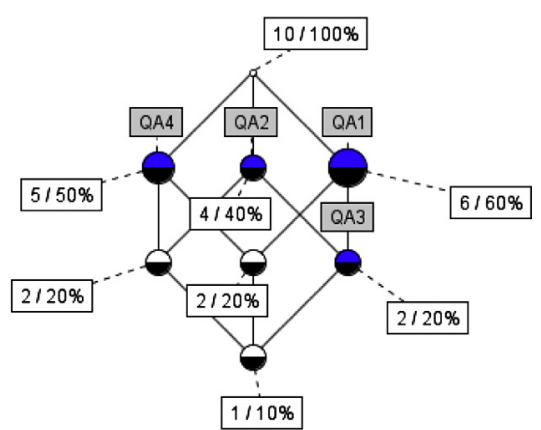

(b)

Fig. 2. Resulting lattices for the sample classification shown in Table 2. 


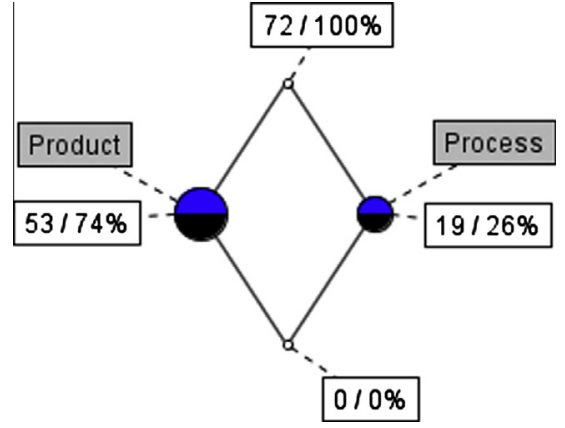

Fig. 3. Distribution of papers among process and product clusters.

To further analyze the distribution of papers across the various quality dimensions, we use the technique of Formal Concept Analysis [38]. This technique allows to group the papers along the different dimensions that are addressed into a lattice and to visualize the commonality of certain quality attributes, that is to say, the level to which papers address the same or different quality attributes. Each node in the lattice identifies a quality attribute and the number of papers addressing specifically this quality attribute. In addition, upward lines denote a subset relationship. Table 2 shows a sample classification of 10 papers along 4 quality attributes. Fig. 2 shows two resulting lattices. In lattice 2a each paper addresses the quality attributes of its node and all the quality attributes of the upward nodes. So, in this lattice we can see that papers 6 and 7 address only QA4. Papers 4, 5 and 8 also address QA4, but simultaneously address other quality attributes as well, i.e. QA2, QA1, and all QAs. The lattice can also be visualized with (cumulative) object counts rather than paper titles, as in $2 \mathrm{~b}$. This allows to easily seeing how often a topic is addressed: the higher the node of a topic, the more often it is addressed. Most interestingly, the graph also visualizes which topics are often addressed together.
Nodes with explicitly attached quality attributes have a full color fill, while half-filled nodes collect papers that (only) combine the quality attributes attached to higher nodes. The size of the nodes is proportional to the number of papers attached to the node.

Considering the general categories of quality types, we can see that of the 72 selected papers, 53 are oriented towards product quality, while 19 address the quality of the modeling process (Fig. 3).

Fig. 4 refines this to author quality types for product quality papers. The complexity of this figure is a visualization of the complexity of the way the terms are used by authors in literature and reveals the difficulty of easily finding a general structure in the literature. There are too many different terms and they are used in a multitude of combinations. The figure may be hard to grasp, but nevertheless, some first conclusions can be drawn. We see that in this cluster of papers, a large majority of the studies (40 of the 53 studies, or $75 \%$ ) aim at proposing guidelines to improve understandability, followed by maintainability (34\%) and complexity (32\%). Fig. 4 also shows that understandability is often discussed in combination with maintainability (28\%) and/or with (general) complexity (23\%). The bottom nodes shows the 4 quality characteristics that were not mentioned by papers that focus on product quality. Surprisingly, completeness is not considered by product quality papers.

A way to simplify these pictures and gain better insight, is to create partial pictures by omitting less frequently addressed dimensions. In Fig. 4, the quality dimension that stands out in terms of frequency, is understandability: it is addressed by 40 out of 53 papers. If we single out the papers that address this quality aspect, we obtain the partial lattice represented in Fig. 5. The figure is still quite complex, which reflects the fact that understandability is discussed together with many combinations of many different quality dimensions. The node at the bottom of the figure lists the quality dimensions that are never discussed together with understandability (at least, using the quality dimensions as named by the authors).

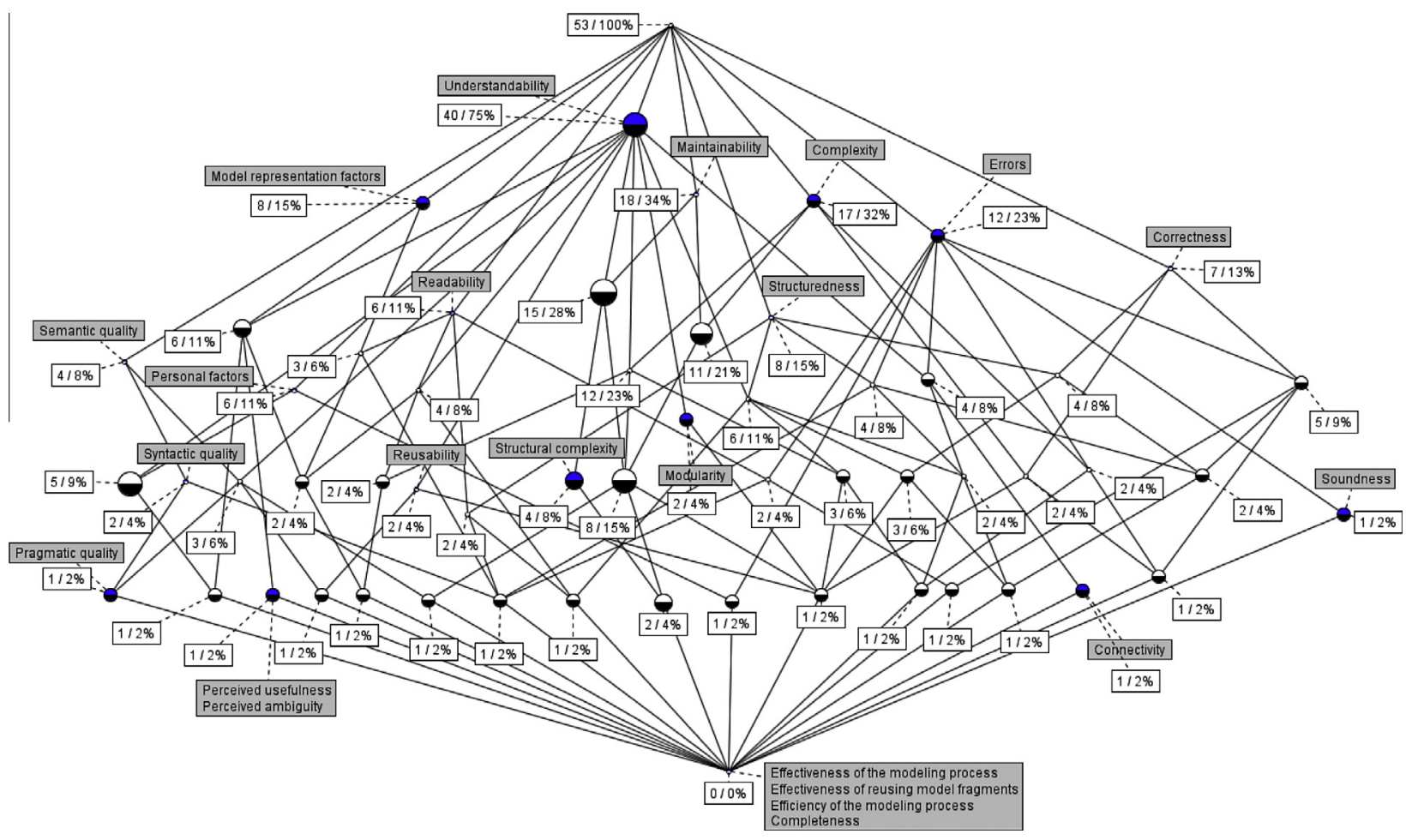

Fig. 4. Quality types based on author criteria for product cluster. 


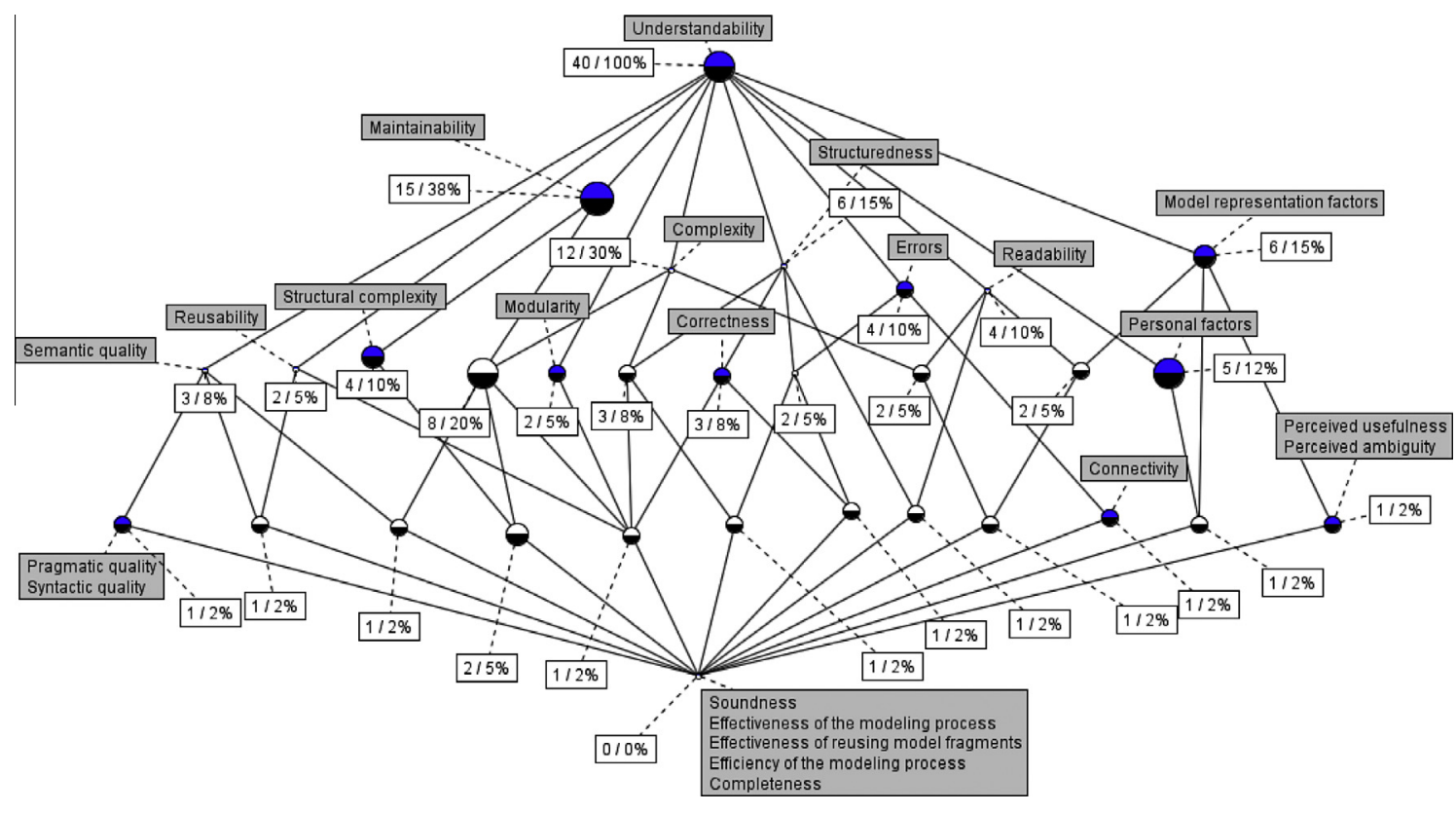

Fig. 5. Partial lattice for papers addressing understandability, based on author criteria for product cluster.

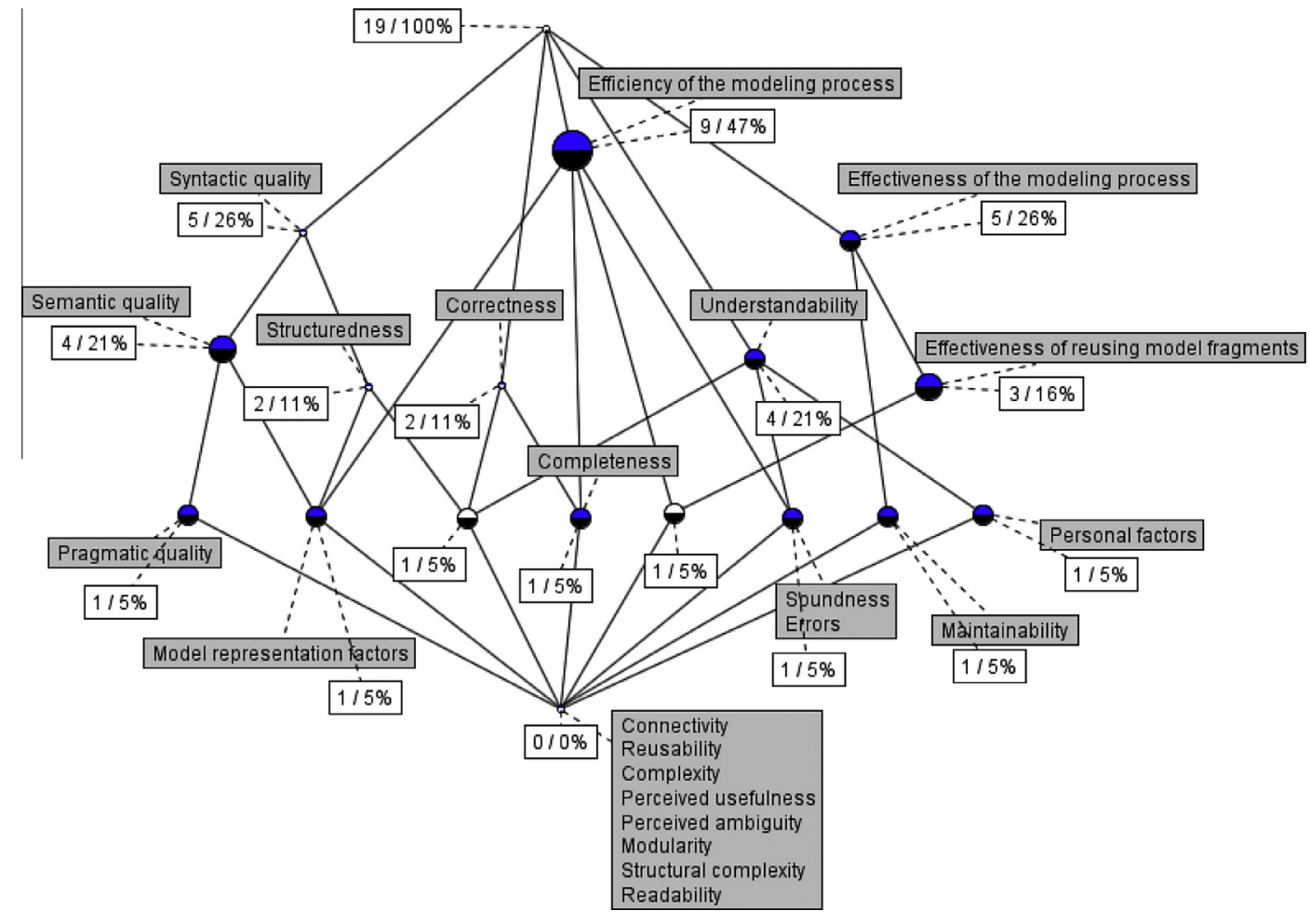

Fig. 6. Quality types based on author criteria for quality of the modeling process cluster.

In the quality of the modeling process cluster (Fig. 6) we see that the efficiency of the modeling process is the most often discussed quality characteristic (47\%), next to the effectiveness of the modeling process (26\%) and the syntactic quality (26\%). Effectiveness of the modeling process is related to the effectiveness of the reuse of model fragments in 3 papers. The papers that fall in this category propose the utilization of recommendation-based modeling tools and the reutilization of modeling artifacts. As can be seen from the bottom node of Fig. 6, many quality characteris- tics that are discussed in product quality research are not discussed in process quality papers.

Here, the quality attributes that stand out in terms of frequency, are the efficiency and effectiveness of the modeling process. If we single out the papers that address these two quality aspects, we obtain the partial lattice represented in Fig. 7. In this figure, we see that 5 papers deal only with efficiency of the modeling process. Four additional papers discuss this quality dimension together with other quality dimensions, each of them with different quality 


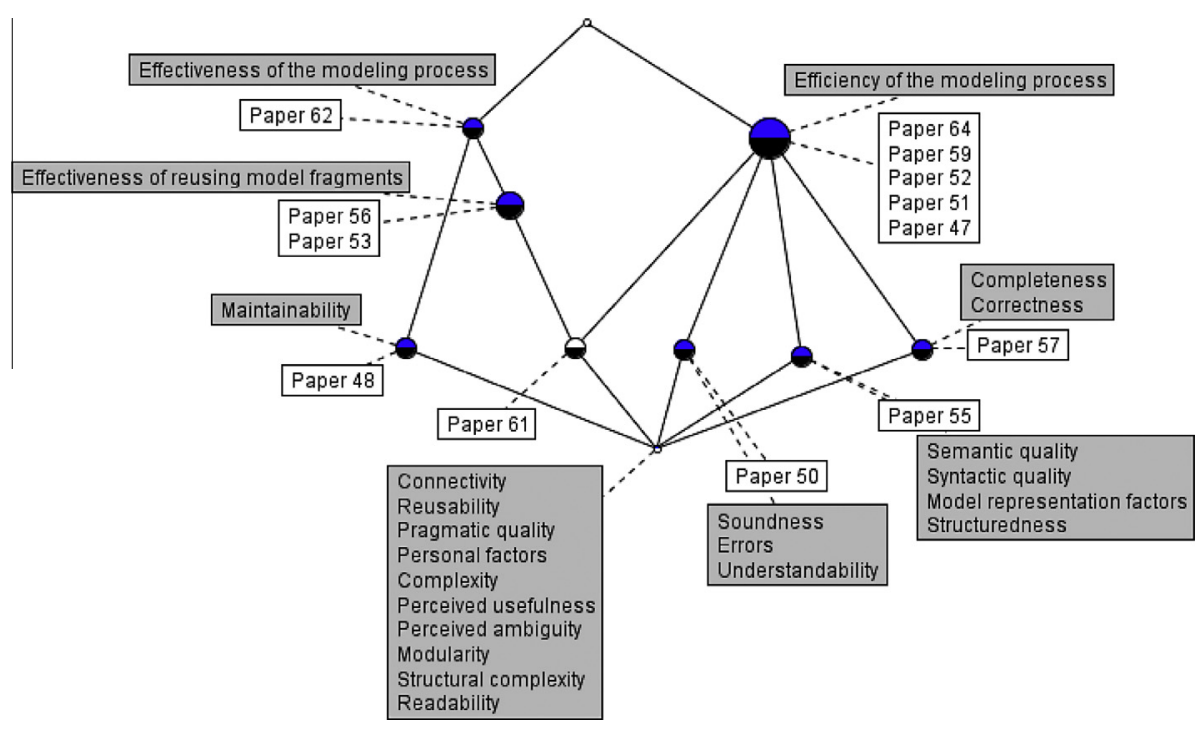

Fig. 7. Partial lattice for papers addressing efficiency and effectiveness of the modeling process, based on author criteria.

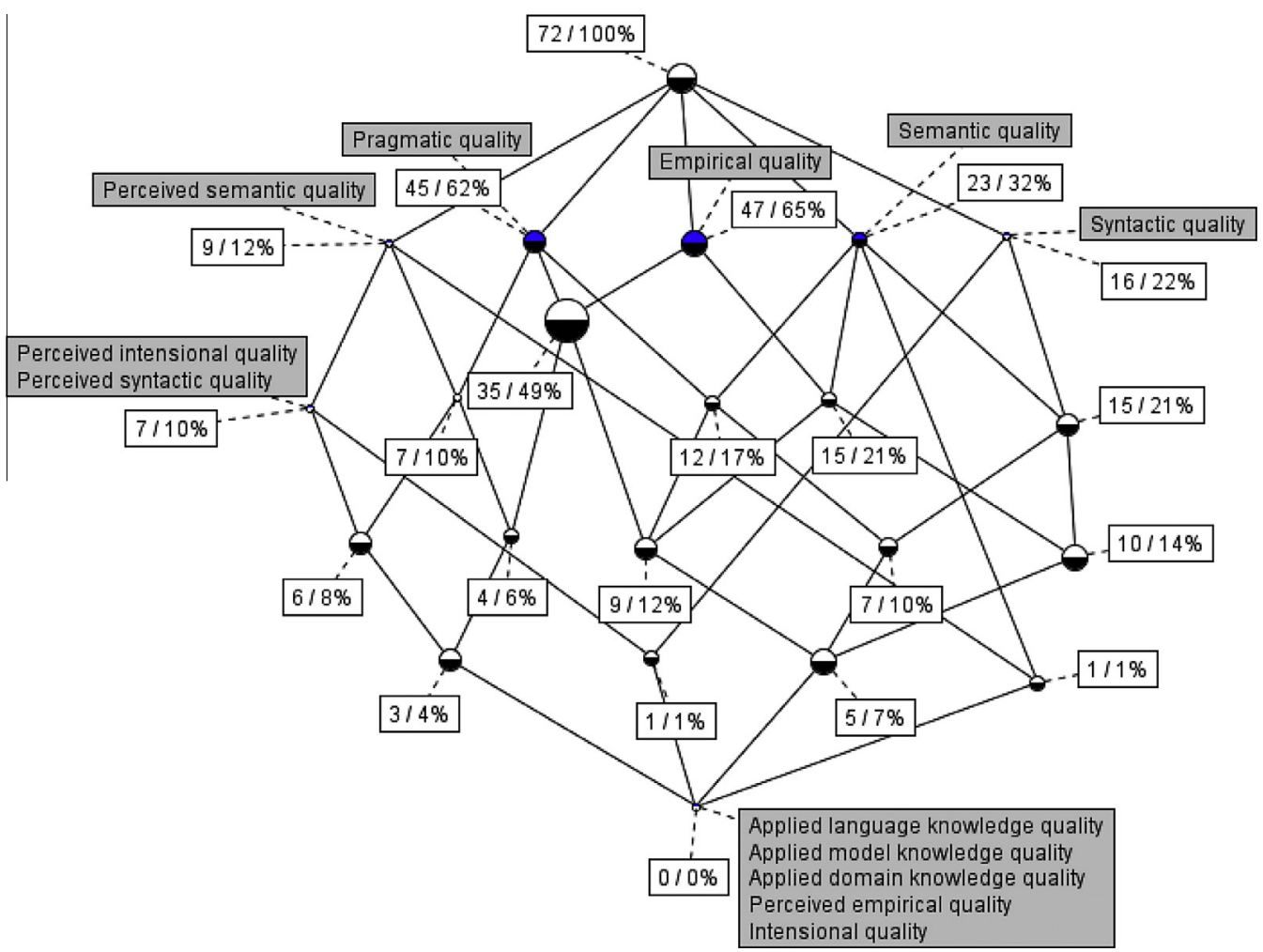

Fig. 8. Quality types based on the CMQF.

dimensions. Only paper 61 combines efficiency of the modeling process with the effectiveness of the modeling process and the effectiveness of reusing model fragments. Looking at the papers that discuss the effectiveness of the process, we see that one paper addresses only this dimension (62), three papers (56, 53 and 61) combine it with effectiveness of reusing model fragments and one (48) combines it with maintainability.

As a result of this review, we verified that in 17 out of the 72 studies authors presented a precise definition of quality by referring to a quality framework or to a standard for quality. In the product quality cluster, this occurred in about one third (28\%) of the studies, while in the quality of the modeling process cluster this occurred only in one tenth (10\%) of the papers.

Classifying papers according to the CMQF quality types reveals that most research efforts have focused on empirical quality (65\%), followed by pragmatic quality (62\%) (see Fig. 8). Fig. 8 also shows that empirical quality is very often dealt in conjunction with pragmatic quality (49\%). Applied language, model and domain knowledge quality, perceived empirical quality and intentional quality are never dealt with. For applied language, model and domain knowledge quality this may seem surprising, as a number of papers discuss personal factors in combination with model understanding. 


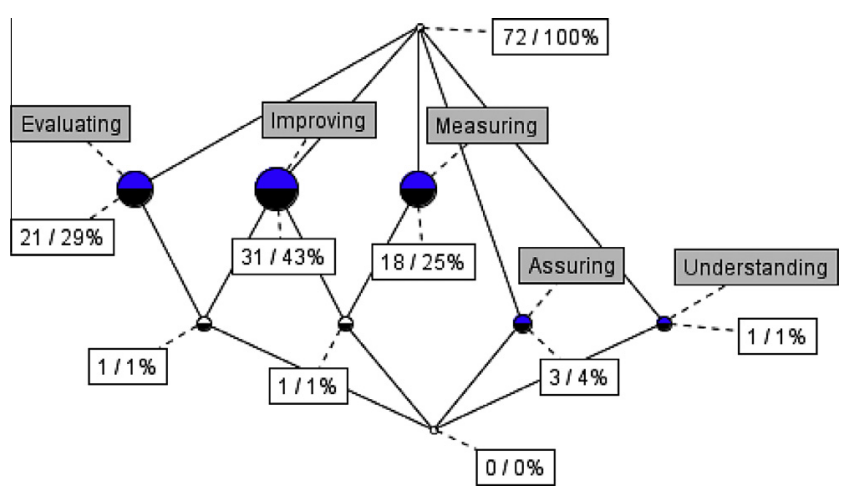

Fig. 9. Classification of papers according their research goal.

However, in these cases, language knowledge or modeling knowledge are considered as factors that impact on pragmatic quality. Yet applied language knowledge quality refers to the use of language knowledge when developing models, which is another quality aspect than when reading models.

Pragmatic quality is a highly investigated quality type. Several guidelines have been proposed to improve the pragmatic quality (i.e. understandability) of the process models. For example, several authors agreed that an increase in size of a model appears to have a negative impact on its pragmatic quality [6,39-43]. Some considerations are available on when a process model would have to be split up into subprocesses to decrease its size. It has been recommended based on empirical findings that process models with more than 50 elements should be decomposed [6]. Another study proposes to decompose the model once it has more than 31 elements [43] based on a threshold definition. Depending on the process modeling language the amount of activities can vary for the same amount of elements [44]. This should be another issue to be aware of when taking a decision on how many elements can be contained in a model. Another example related to pragmatic quality are guidelines about the label style for activities in a process model. Some studies affirmed that it is a good practice to use verb-object activity labeling (ex. [6]). The use of a domain-specific vocabulary is also recommended to improve understanding and semantic quality of the model $[14,16,45]$.
A representative aspect for empirical quality is the readability of a conceptual representation [8]. Some of the papers included in this set deal with layout aspects that improve readability. Other guidelines propose to avoid crossings within a graphical layout $[46,47]$, the use of colors to highlight graphical elements in the process model $[14,48]$, or to avoid edge bends within a model [47], among others.

RQ2: How mature is the business process modeling research field?

(a) What are the business process modeling quality research
goals?

The purpose of investigating the goals of the research papers is to determine where the main focus of process modeling quality research lies. As shown in Fig. 9 the main focus lies on improving (43\%), evaluating (29\%) and measuring (25\%) quality. The latter papers develop quality metrics to characterize BP models quality. Assuring and understanding together account for less than $6 \%$ of the papers in the SLR. This is an indication that the field of modeling quality still needs to gain in maturity. Indeed, quality assurance refers to administrative and procedural activities implemented in a quality system, which in turn requires setting in place quality policies and quality objectives. This obviously requires understanding modeling quality and a sound set of quality metrics, ways to evaluate quality and guidelines to improve quality.

Fig. 10 shows the combined classification into clusters as well as along research goals. On the right hand side, we can see that product quality research (74\%) is approximately evenly distributed across improving (24\%), evaluating (28\%) and measuring (25\%). On the left hand side, we see that process quality papers (26\%) are almost exclusively directed at improving quality (19\%), whereas only 3 papers deal with assuring quality, 1 paper with evaluating quality and 1 paper with understanding quality.

(b) Which research methods are more/less used in the research area?

The results of the research methods classification effort are shown in Fig. 11. Experimentation is the most frequently used research method (32/44\%), followed by proposals for addressing

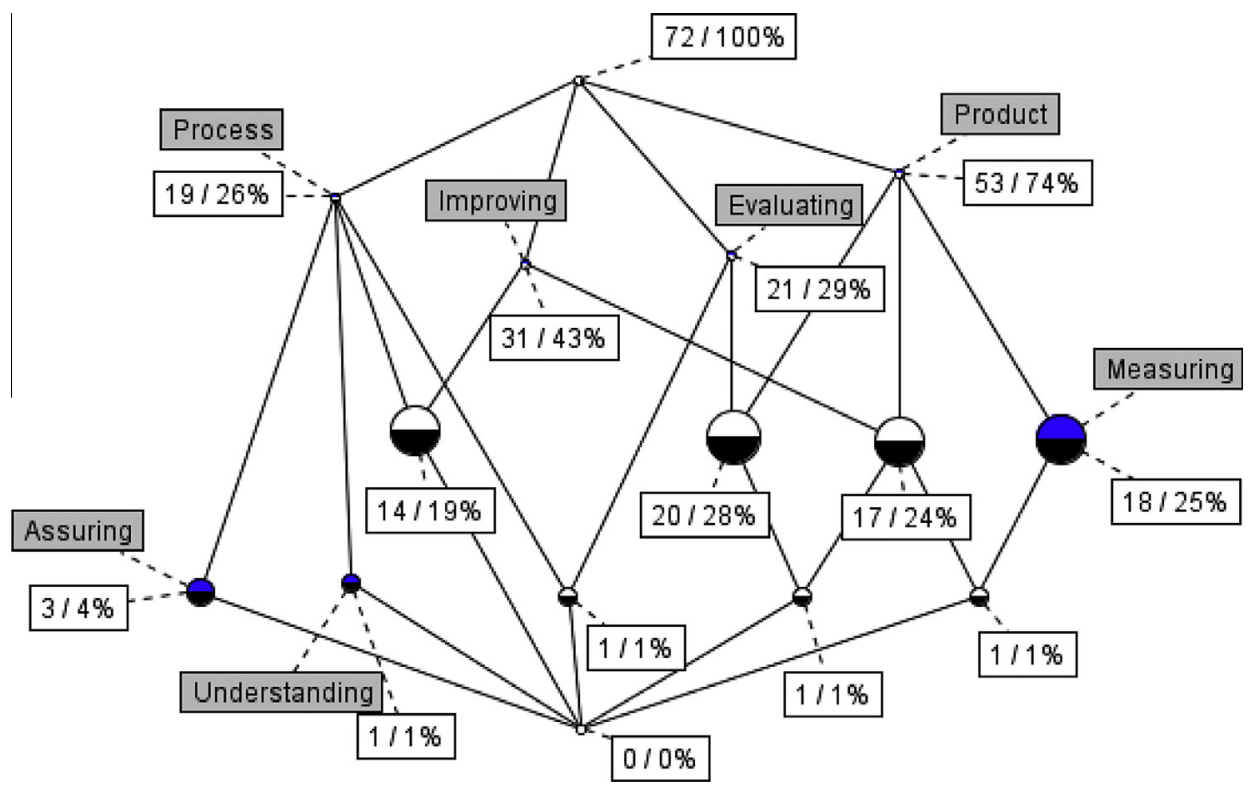

Fig. 10. Relationship between research goals and clusters. 


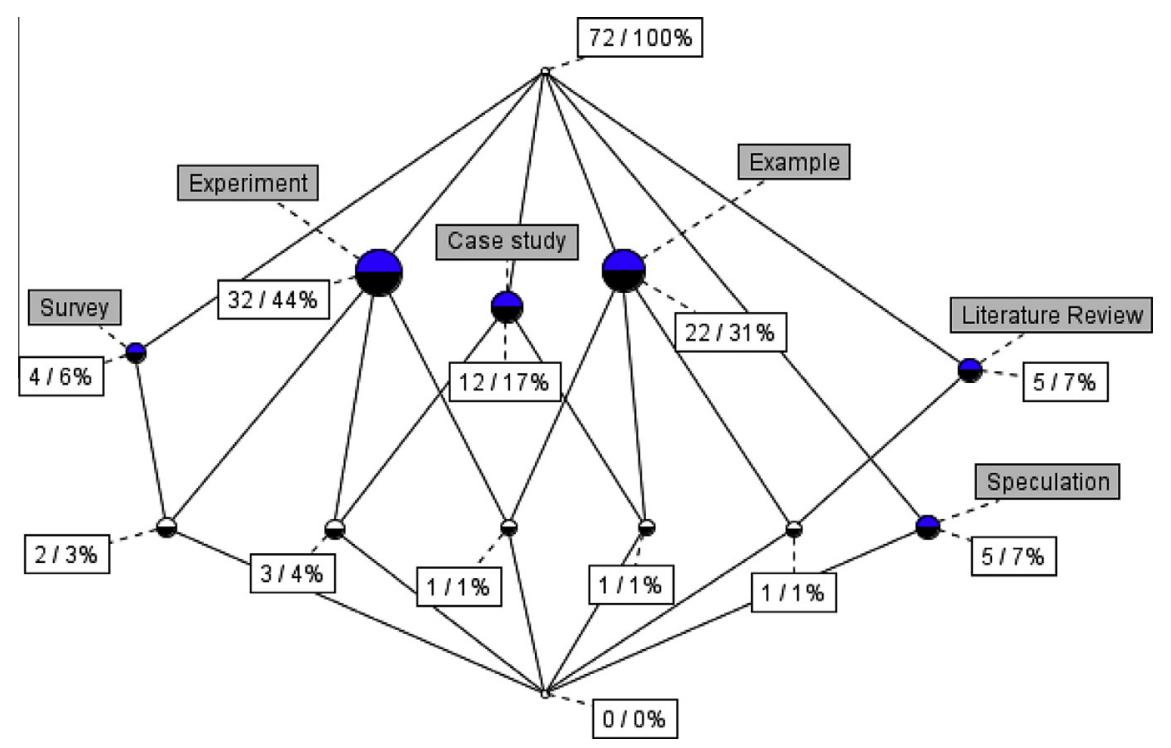

Fig. 11. Research methods overview.

Table 3

Relationship between research methods and quality types.

\begin{tabular}{|c|c|c|c|c|c|c|c|c|c|}
\hline \multirow[b]{2}{*}{ Experiment } & \multirow{2}{*}{$\begin{array}{l}\text { Total } \\
32\end{array}$} & \multicolumn{2}{|c|}{ Empirical quality } & \multicolumn{2}{|c|}{ Pragmatic quality } & \multicolumn{2}{|c|}{ Semantic quality } & \multicolumn{2}{|c|}{ Syntactic quality } \\
\hline & & 20 & $63 \%$ & 23 & $72 \%$ & 11 & $34 \%$ & 11 & $34 \%$ \\
\hline Example & 22 & 15 & $68 \%$ & 9 & $41 \%$ & 5 & $23 \%$ & 1 & $5 \%$ \\
\hline Case study & 12 & 9 & $75 \%$ & 10 & $83 \%$ & 5 & $42 \%$ & 3 & $25 \%$ \\
\hline
\end{tabular}

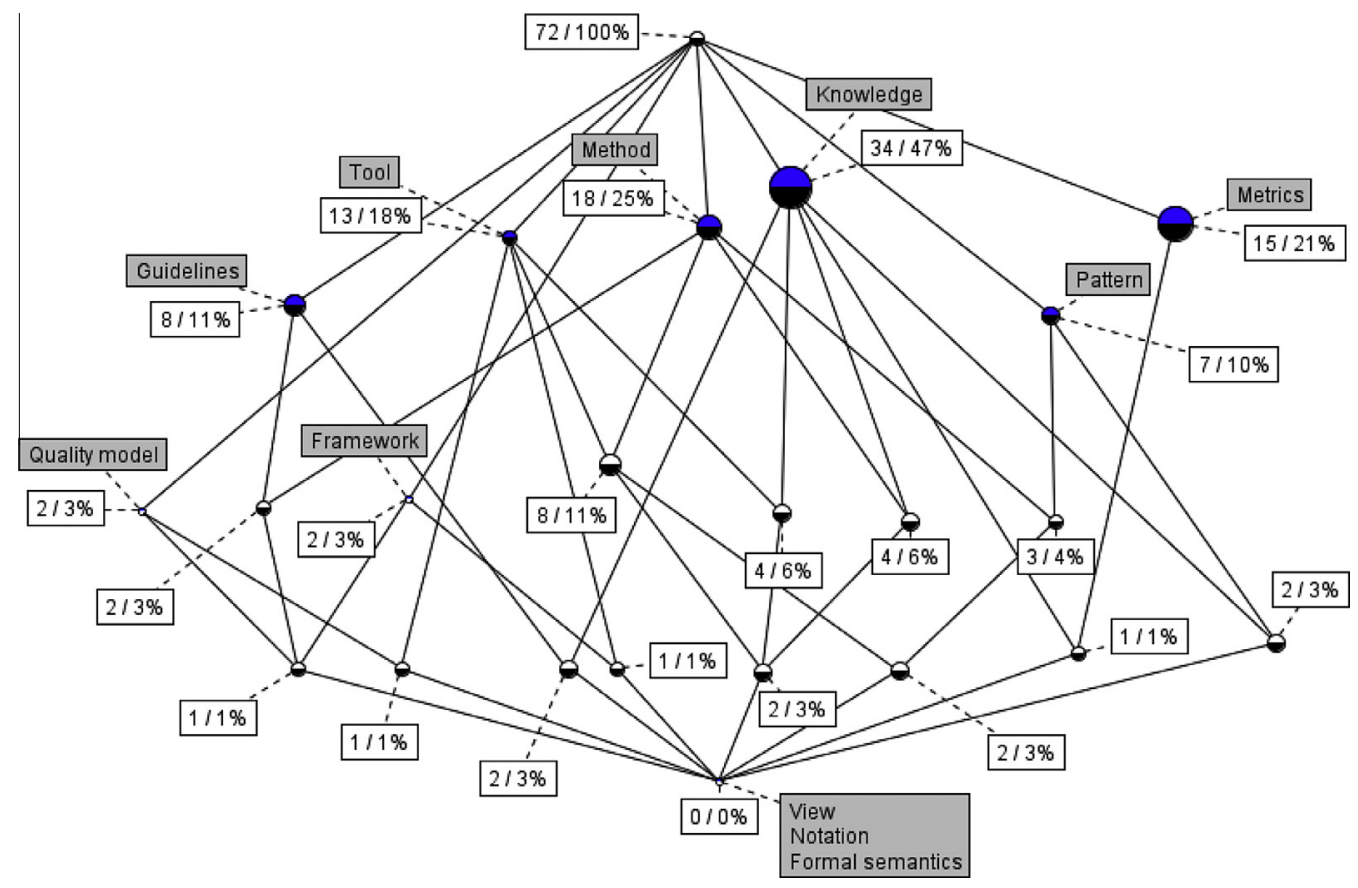

Fig. 12. Research result overview.

business process modeling quality illustrated through examples (22/31\%), and case studies (12/17\%). Almost three quarters (73\%) of the papers that perform experiments belong to the product quality cluster. In seven experiments, the participants were undergraduate or postgraduate students. Only four experiments used experienced modelers from industry and academia.

The use of a descriptive research method [37] is rather scarce in the set of papers of this SLR. This type of research method refers to speculations (or informed argument). This category accounts for $7 \%$ of the papers of this SLR. Papers the main contribution of which is to perform literature reviews to propose future research are also limited in this review (5/7\%).

The majority of the experiments focus on pragmatic (72\%) and empirical (63\%) quality. Experiments that focus on pragmatic quality demonstrate how different business process models factors affect model understanding. Examples were mainly used in papers 
on empirical quality (68\%). Finally, we can see that case studies were most frequently used to investigate empirical and pragmatic quality as well. Table 3 shows the relationship between the most common research methods found in this review (i.e. experiment, example and case study) and the most common quality types (i.e. empirical, pragmatic, semantic and syntactic quality).

In total, 41 studies were empirically validated. This represents $57 \%$ of the total amount of studies. For the product quality cluster, $62 \%$ of the research was thoroughly validated. For the process modeling quality cluster, $42 \%$ of the studies were empirically validated.

(c) Which type of research results are provided on business process modeling quality research works?

To answer RQ2 (c) we classified papers according the scheme proposed in [22]. Obviously, all research papers produces some kind of knowledge, but in the classification proposed in [22], "knowledge" refers to intangible results, whereas the other types of results are tangible artifacts like metrics, guidelines, patterns, tools, and so on.

According to this classification, the most common research results type is knowledge (47\%) (see Fig. 12). Three quarters (76\%) of these papers belongs to the product quality cluster. The second most frequent type of results are concrete methods to prevent or correct deficiencies in process models (25\%). Most of the papers in this set present approaches, techniques and methodologies for process modeling that should result in better model quality. More than half $(56 \%)$ of these papers belong to the process modeling quality cluster while $44 \%$ belong to the product quality cluster.

On the third place we find papers that propose metrics. Research in this category mainly includes conceptual work on process model metrics (15/21\%), partially inspired by software measurement and experimental work on validating process model metrics. All (100\%) these papers belongs to the product quality cluster. A reason for this could be that metrics are suggested to quantify quality characteristics of the process models (i.e., the product) such as complexity, size, coupling, cohesion, among others. Since most of the authors do not follow any standard for their quality concepts and describe measures according to their own insight, in [24] authors proposed the use of the ISO 9126 standard [49] as a reference for quality. This standard proposes characteristics and sub-characteristics very close to those described by many authors as measurable concepts in their metrics works. In this regard, we found that usability (having understandability as a sub-characteristic, 10 papers) and maintainability (9 papers) were the principal measurable concepts presented in the papers that propose metrics.

\section{Discussion of the results and future work}

The research presented here is a systematic literature review of papers dealing with business process modeling quality based on the original SLR guidelines as proposed by Kitchenham in [26]. We analyzed 1061 articles published between 2000 and 2013, of which 72 were considered to be addressing quality aspects of business process modeling as part of the process discovery phase. Among these studies, 53 papers address the quality of a business process model as the end product of a modeling exercise and 19 papers address the quality of the modeling process itself. We classified papers according to the quality aspects they address as named by authors and according to the Conceptual Modeling Quality Framework (CMQF).
On the side of product quality, authors focus essentially on model understanding, starting from a number of empirical quality attributes. Overall, in terms of the CMQF, the physical and learning layers draw the majority of the attention of researchers, whereas the knowledge and development layers are hardly investigated. While a number of authors did investigate the impact of language and modeling knowledge on pragmatic quality, we did not find any study that investigates the impact of applied language or modeling knowledge quality on the final quality of the model from a model development perspective.

The landscape of research on the quality of the modeling process is quite scattered. The main emphasis is put on enhancing the efficiency of modeling by means of promoting the reuse of existing process artifacts.

According to this, an area of further research is to investigate the knowledge layer and the development layer: How can we measure the knowledge a person possesses about a domain, business process modeling concepts and a business process modeling language? And how does this knowledge affect the development of business process models? Good modelers rely mainly on their personal experience, and the tacit knowledge they have developed over time is difficult to transfer to junior modelers [50]. Therefore, a better understanding of the interplay between the knowledge and the development layer would be of particular interest in the context of teaching business process modeling.

As a result of this classification effort, we conclude that guidelines to improve the understandability of business process models are the most researched area. Using the terminology of the CMQF, empirical and pragmatic quality types are the two quality dimensions where most of the research labor occurred. This suggests that more research in semantic may be called for. More insights into the constituents of semantic quality will contribute to the achievement of business process models that accurately and completely capture the meaning of the physical domain. Research on syntactic quality (different from algorithms for the formal verification of process models for e.g. deadlock or safety, see exclusion criteria) is also scarce. This aspect is, however, strongly linked to the quality of a modeling language definition and it is solved as soon as the syntax of a language is given by its meta-model (and maybe some OCL expressions). Given a clear definition of a modeling language, modeling tools can assist the modeler in achieving high syntactical quality through the syntax checker, so it is not surprising that researchers focus on other topics.

In order to assess the current maturity of business process modeling quality research, we classified business process modeling quality literature along their research goals, research methods, and type of results. Our findings are that most of business process modeling quality research focuses on improving and evaluating the quality of models. Very little research has been performed around assuring and understanding business process quality. True quality assurance requires a quality system consisting of, amongst others, a coherent set of quality policies, quality objectives, and quality metrics. It is a completely open issue how such a quality system should be developed.

As an additional result of this SLR we obtained that $57 \%$ of the collected proposals performed some kind of empirical validation. A positive trend is that more recent work spends attention to the validation of the research results. Despite this finding, there seems to be a gap in our knowledge as to which of the existing research proposals offer the best perspective of being successful in practice. The most frequently used research method is experimentation with students. Large scale validations with practitioners to ensure the relevance of the proposals for business process modeling practitioners are in demand. This validation is of particular importance considering the threat of low external validity of student experi- 
ments in information systems research, as stated in [3]. Experiments using practitioners and tasks of real world complexity will increase the generalizability and usability of the proposals to practice.

According to the classification scheme proposed in [22], the most common research result is intangible knowledge, followed by methods, metrics and tools. The insight that most research only leads to intangible knowledge instead of methods/metrics/tools/ guidelines leaves the question open: How will these insights flow into praxis? An interest in and demand for guidelines is substantiated by the fact that the paper "Seven process modeling guidelines (7PMG)" [6] has been cited more than 250 times already since it was published only three years ago. Clearly, only seven guidelines cannot cover everything that a modeler needs to know. For example, this particular paper does not tell how to decompose a business process model - only that is need to be decomposed it beyond a certain size of the model. Also, more research is needed with respect to quality metrics. In particular, the analysis of the results reveals that a large amount of research on metrics is not addressing guidelines and vice versa. Existing quality metrics would need a critical review to make them applicable as a measurement to evaluate the outcome of applying guidelines.

An additional finding that is worth emphasizing is that only $24 \%$ of the papers presented a precise definition of quality in their studies by referring to a quality framework or standard for quality. This clearly makes it difficult to develop a unified view on the state of the research area. This insight points at the value of further research into the definition of business process modeling quality by creating a direct bridge between business process modeling quality research on the one hand and quality frameworks or a standard for quality on the other. The use of the CMQF allowed for a more unified view on the types of quality addressed by current research. It seems reasonable to suggest that also this framework could be improved in different ways. We will consider a number of directions in this regard.

First, sometimes authors use terms interchangeably, whereas the CMQF considers them as different quality dimensions. For example, readability and understandability are quality types between which the CMQF makes a clear distinction, while some authors tend to use these terms as synonyms. Further clarification and illustration of the definitions would enhance the ease of use of the CMQF to frame model quality issues.

Second, although the CMQF already addresses many dimensions of model quality, it was not always easy to classify papers because authors sometimes single out subaspects of a single dimension of the CMQF (see Section 4.2). This might indicate that the model may benefit from further refinements for some dimensions.

Third, many author-defined quality types are classified as empirical quality by the CMQF. Many of these author-defined quality terms originate from papers that involve some kind of business process metric. Often, business process metrics are directed towards assessing the quality of a process as a (software) design artifact, addressing aspects such as maintainability, structural complexity, modularity, complexity, reusability, and modifiability. On the other hand, the CMQF and the research on model and modeling process quality emphasize the requirements engineering perspective, meaning that the focus lies on the use of a model for representing a domain and communicating with human stakeholders. As a result, the CMQF largely misses specific dimensions relating to the use of a model as an executable artifact. In particular the framework could be further completed by addressing the perspective of a model as a description of how a business operates. This may include typical software (design) quality attributes such as reliability, maintainability, (computer) time and resource usage.
A final research area that seems worthwhile to pursue further concerns the quality of the modeling process. Such research should not only look at the different tasks in a modeling process, such as elicitation, modeling and validation, but also look at the contextual factors. For example, the choice of the modeling language may affect the syntactic, semantic and pragmatic quality of a model. Also, tool support is likely to have an impact on the syntactic quality of the models created and may help the integration with related models. In future work, it would be interesting to offer a complete set of validated guidelines for business process modeling practitioners that assess these types of contextual factors as well.

\section{Conclusions}

This study presents a systematic literature review on business process modeling quality. Its objective was to assess the state of the art of this research area. This review led the following conclusions:

- There have been more publications on the quality of the process models as a product than on the quality of the modeling process.

- There is no generally accepted framework of model quality types: authors refer to quality types using many different quality names and not a standard for quality. Only one fourth of the studies used a precise definition of quality. Among the used quality terms, most research focuses on understandability and maintainability for the product cluster and on efficiency and effectiveness of the modeling process for the process cluster. In terms of the CMQF, most research focuses on empirical and pragmatic quality aspects. The use of the CMQF as a mean to unify the different quality terms was a positive experience. Nevertheless, the application of the framework revealed that it can be improved in different ways.

- Between the different research goals, the main focus lies on improving, evaluating and measuring quality. Little research effort has been spent on assuring and understanding business process modeling quality. Among the various research methods, experimentation is the most popular one, followed by the use of examples and case studies. A little more than half of the papers performed empirical validations, and experiments were mostly conducted with students. Descriptive research methods are scarce in this research area. The results from published research most often take the form of intangible knowledge. Also, the results in form of methods and metrics are observed within the resulting paper set of this SLR.

The above mentioned aspects provide indications that the field of modeling quality still needs to gain in maturity. Based on our interpretation of the SLR results, we suggest further research on developing a more comprehensive quality framework, on investigating the knowledge and development layer, and on the process of modeling itself. From our study, it has become clear that there are plenty of open research questions in the area of business process modeling quality that seems worthwhile to pursue, both from an academic and a practical perspective.

\section{Acknowledgements}

The authors thank VLIR-UOS program for the sponsorship of this research. We also thank Karel Dejaeger and Pieter Hens for the valuable help offered during the development of the article, and the anonymous reviewers for their insightful comments which helped to improve this paper. 


\begin{tabular}{|c|c|c|c|}
\hline Number & Author & Year & Title \\
\hline Paper 1 & Mendling, J.; Reijers, H.A.; van der Aalst, W.M.P. & 2010 & Seven process modeling guidelines \\
\hline Paper 2 & Reijers, H.A.; Mendling, J.; Dijkman, R.M. & 2011 & $\begin{array}{l}\text { Human and automatic modularizations of process models to } \\
\text { enhance their comprehension }\end{array}$ \\
\hline Paper 3 & Weber, B.; Reichert, M.; Mendling, J.; Reijers, H.A. & 2011 & Refactoring large process model repositories \\
\hline Paper 4 & Reijers, H.A.; Mendling, J. & 2011 & $\begin{array}{l}\text { A Study Into the Factors That Influence the Understandability of } \\
\text { Business Process Models }\end{array}$ \\
\hline Paper 5 & Mendling, J.; Reijers, H.A.; Recker, J. & 2010 & $\begin{array}{l}\text { Activity labeling in process modeling: Empirical insights and } \\
\text { recommendations }\end{array}$ \\
\hline Paper 6 & Mendling, J.; Recker, J.; Reijers, H.A & 2010 & On the Usage of Labels and Icons in Business Process Modeling \\
\hline Paper 7 & Gruhn, V.; Laue, R. & 2007 & What business process modelers can learn from programmers \\
\hline Paper 8 & Mendling, J.; Strembeck, M. & 2008 & Influence Factors of Understanding Business Process Models \\
\hline Paper 9 & Reijers, H.A.; Freytag, T.; Mendling, J.; Eckleder, A. & 2011 & Syntax highlighting in business process models \\
\hline Paper 10 & Hornung, T.; Koschmider, A.; Lausen, G. & 2008 & $\begin{array}{l}\text { Recommendation Based Process Modeling Support: Method and } \\
\text { User Experience }\end{array}$ \\
\hline Paper 11 & Figl, K.; Laue, R. & 2011 & Cognitive Complexity in Business Process Modeling \\
\hline Paper 12 & $\begin{array}{l}\text { La Rosa, M.; ter Hofstede, A.H.M.; Wohed, P.; Reijers, H.A.; } \\
\text { Mendling, J.; van der Aalst, W.M.P. }\end{array}$ & 2011 & $\begin{array}{l}\text { Managing Process Model Complexity via Concrete Syntax } \\
\text { Modifications }\end{array}$ \\
\hline Paper 13 & $\begin{array}{l}\text { La Rosa, M.; Wohed, P.; Mendling, J.; ter Hofstede, A.H.M.; } \\
\text { Reijers, H.A.; van der Aalst, W.M.P. }\end{array}$ & 2011 & $\begin{array}{l}\text { Managing Process Model Complexity via Abstract Syntax } \\
\text { Modifications }\end{array}$ \\
\hline Paper 14 & $\begin{array}{l}\text { Mendling, J.; Verbeek, H.; Dongen, B.; van der Aalst, } \\
\text { W.M.P.; Neumann, G. }\end{array}$ & 2008 & $\begin{array}{l}\text { Detection and Prediction of Errors in EPCs of the SAP Reference } \\
\text { Model }\end{array}$ \\
\hline Paper 15 & Cardoso, J.; Mendling, J.; Neumann, G.; Reijers, H.A. & 2006 & A discourse on complexity of process models \\
\hline Paper 16 & Abdul, A.A.; TiengWei, G.K.; Muketha, G.M.; Wen, W.P. & 2008 & $\begin{array}{l}\text { Complexity metrics for measuring the understandability and } \\
\text { maintainability of business process models using goal-question- } \\
\text { metric (GQM) }\end{array}$ \\
\hline Paper 17 & Khlif, W.; Makni, L.; Zaaboub, N.; Ben-Abdallah, H. & 2009 & Quality metrics for business process modeling \\
\hline Paper 18 & Lassen, K.B.; van der Aalst, W.M.P. & 2009 & Complexity metrics for Workflow nets \\
\hline Paper 19 & Rolon, E.; Ruiz, F.; Garcia, F.; Piattini, M. & 2006 & Applying Software Metrics to evaluate Business Process Models \\
\hline Paper 20 & $\begin{array}{l}\text { Rolon, E.; Sanchez, L.; Garcia, F.; Ruiz, F.; Piattini, M.; } \\
\text { Caivano, D.; Visaggio, G. }\end{array}$ & 2009 & Prediction models for BPMN usability and maintainability \\
\hline Paper 21 & Tonbul, G.; Misra, S. & 2009 & Error density metrics for business process model \\
\hline Paper 22 & $\begin{array}{l}\text { Debnath, N.; Salgado, C.; Peralta, M.; Riesco, D.; } \\
\text { Montejano, G. }\end{array}$ & 2010 & $\begin{array}{l}\text { Optimization of the business process metrics definition according } \\
\text { to the bpdm standard and its formal definition in OCL }\end{array}$ \\
\hline Paper 23 & Khlif, W.; Zaaboub, N.; Ben-Abdallah, H. & 2010 & Coupling metrics for business process modeling \\
\hline Paper 24 & Sánchez-González, L.; Garcia, F.; Mendling, J.; Ruiz, F. & 2010 & $\begin{array}{l}\text { Quality Assessment of Business Process Models Based on } \\
\text { Thresholds }\end{array}$ \\
\hline Paper 25 & Laue, R.; Mendling, J. & 2008 & $\begin{array}{l}\text { The impact of structuredness on error probability of process } \\
\text { models }\end{array}$ \\
\hline Paper 26 & Laue, R.; Gruhn, V. & 2007 & Approaches for business process model complexity metrics \\
\hline Paper 27 & Laue, R.; Mendling, J. & 2010 & $\begin{array}{l}\text { Structuredness and its significance for correctness of process } \\
\text { models }\end{array}$ \\
\hline
\end{tabular}
Information Systems

Computers in Industry Ieee Transactions on Systems, Man, and Cybernetics - Part A Information Systems

International Journal of Information System, Modeling and Design

Science of Computer Programming

International Conference on Business Information Systems Decision Support Systems

Conceptual Modeling Conference (ER 2008)

International Conference on Advanced Information Systems Engineering (CAISE 2011)

Ieee Transactions on Industrial Informatics

Ieee Transactions on Industrial Informatics

\section{Data \& Knowledge Engineering}

Business Process Management Workshops (BPM 2006) International Journal of Computer Science and Network Security

Wseas International Conference on Applied Computer Science (Acs'09)

Information and Software Technology

CLEI-Electronic Journal

IEEE Conference on Commerce and Enterprise Computing

International Symposium on Computer and Information Sciences (ISCIS'09)

(Alference on Computer Systems and

Applications (AICCSA 2010)

WSEAS Transactions on Computers

On the Move Confederated International Conference

International United Informational Systems Conference (UNISCON 2008)

Technologies for Business Information Systems Information Systems and E-Business Management

W.M.P.; Cardoso, 


\begin{tabular}{|c|c|c|c|c|}
\hline Number & Author & Year & Title & Source \\
\hline Paper 29 & Mendling, J.; Neumann, G.; van der Aalst, W.M.P. & 2007 & $\begin{array}{l}\text { Understanding the occurrence of errors in process models based on } \\
\text { metrics }\end{array}$ & OTM Confederated International Conference and Workshop \\
\hline Paper 30 & Vanderfeesten, I.; Cardoso, J.; Reijers, H.A. & 2007 & A weighted coupling metric for business process models & $\begin{array}{l}\text { International Conference on Advanced Information Systems } \\
\text { Engineering (CAISE 2007) }\end{array}$ \\
\hline Paper 31 & Reggio, G.; Leotta, M.; Ricca, F. & 2011 & $\begin{array}{l}\text { "Precise is better than light" a document analysis study about } \\
\text { quality of business process models }\end{array}$ & Empirical Requirements Engineering International Workshop \\
\hline Paper 32 & Mendling, J.; Reijers, H.A.; Cardoso, J. & 2007 & What makes process models understandable? & International Conference on Business Process Management \\
\hline Paper 33 & $\begin{array}{l}\text { Rolon, E.; Garcia, F.; Ruiz, F.; Piattini, M.; Visaggio, C.A.; } \\
\text { Canfora, G. }\end{array}$ & 2008 & Evaluation of BPMN models quality - A family of experiments & $\begin{array}{l}\text { International Conference on Evaluation of Novel Approaches } \\
\text { to Software Engineering (Enase 2008) }\end{array}$ \\
\hline Paper 34 & Gruhn, V.; Laue, R. & 2011 & $\begin{array}{l}\text { Detecting Common Errors in Event-Driven Process Chains by Label } \\
\text { Analysis }\end{array}$ & Enterprise Modelling and Information Systems Architectures \\
\hline Paper 35 & Arkilic, I.G.; Reijers, H.A; Goverde, R. & 2013 & How Good Is an AS-IS Model Really? & Business Process Management Workshops \\
\hline Paper 36 & $\begin{array}{l}\text { Dumas, M.; La Rosa, M.; Mendling, J.; Mäesalu, R.; Reijers, } \\
\text { H.A; Semenenko, N. }\end{array}$ & 2012 & $\begin{array}{l}\text { Understanding Business Process Models: The Costs and Benefits of } \\
\text { Structuredness }\end{array}$ & $\begin{array}{l}\text { International Conference on Advanced Information Systems } \\
\text { Engineering (CAISE 2012) }\end{array}$ \\
\hline Paper 37 & Mendling, J.; Neumann, G. & 2007 & Error metrics for business process models & $\begin{array}{l}\text { International Conference on Advanced Information Systems } \\
\text { Engineering (CAISE 2007) }\end{array}$ \\
\hline Paper 38 & Mendling, J. ; Reijers, H.A. & 2008 & The Impact of Activity Labeling Styles on Process Model Quality & $\begin{array}{l}\text { AIS SIGSAND European Symposium on Analysis, Design, Use } \\
\text { and Societal Impact of Information Systems (SIGSAND Europe } \\
\text { 2008) }\end{array}$ \\
\hline Paper 39 & Mendling, J.; Sánchez-González, L; García, F.; La Rosa, M. & 2012 & $\begin{array}{l}\text { Thresholds for error probability measures of business process } \\
\text { models }\end{array}$ & Journal of Systems and Software \\
\hline Paper 40 & Mendling, J.; Strembeck, M.; Recker, J. & 2012 & $\begin{array}{l}\text { Factors of process model comprehension-Findings from a series of } \\
\text { experiments }\end{array}$ & Decision Support Systems \\
\hline Paper 41 & Reijers, H.A.; Mendling, J. & 2008 & Modularity in Process Models: Review and Effects & International Conference on Business Process Management \\
\hline Paper 42 & Rolón, E.; Cardoso, J.; García, F.; Ruiz, F.; Piattini, M. & 2009 & $\begin{array}{l}\text { Analysis and Validation of Control-Flow Complexity Measures } \\
\text { with BPMN Process Models }\end{array}$ & $\begin{array}{l}\text { International Workshop on Business Process Modeling, } \\
\text { Development and Support (BPMDS 2009) }\end{array}$ \\
\hline Paper 43 & Sánchez-González, L.; García, F.; Ruiz, F.; Mendling, J. & 2012 & $\begin{array}{l}\text { Quality indicators for business process models from a gateway } \\
\text { complexity perspective }\end{array}$ & Information \& Software Technology \\
\hline Paper 44 & Van Dongen, B.; Mendling, J.; Van Der Aalst, W.M.P. & 2006 & Structural Patterns for Soundness of Business Process Models & $\begin{array}{l}\text { Enterprise Distributed Object Computing Conference (EDOC } \\
\text { 2006) }\end{array}$ \\
\hline Paper 45 & Schrepfer, M.; Wolf, J.; Mendling, J.; Reijers, H.A. & 2009 & The impact of secondary notation on process model understanding & $\begin{array}{l}\text { The Practice of Enterprise Modeling Working Conference } \\
\text { (PoEM 2009) }\end{array}$ \\
\hline Paper 46 & Gruhn, V.; Laue, R. & 2007 & Good and Bad Excuses for Unstructured Business Process Models & $\begin{array}{l}\text { European conference on pattern languages of programs } \\
\text { (EuroPLoP 2007) }\end{array}$ \\
\hline Paper 47 & Castela, N.; Tribolet, J.; Guerra, A.; Lopes, E. & 2002 & $\begin{array}{l}\text { Survey, analysis and validation of information for business process } \\
\text { modeling }\end{array}$ & $\begin{array}{l}\text { International Conference on Enterprise Information Systems } \\
\text { (ICEIS 2002) }\end{array}$ \\
\hline Paper 48 & Ferreira, J.E.; Takai, O.K.; Malkowski, S.; Pu, C. & 2010 & $\begin{array}{l}\text { Reducing Exception Handling Complexity in Business Process } \\
\text { Modeling and Implementation: The WED-Flow Approach }\end{array}$ & On the Move Confederated International Conference \\
\hline Paper 49 & Recker, J.; Dreiling, A. & 2011 & $\begin{array}{l}\text { The Effects of Content Presentation Format and User } \\
\text { Characteristics on Novice Developers' Understanding of Process } \\
\text { Models }\end{array}$ & Communications of the Association for Information Systems \\
\hline Paper 50 & $\begin{array}{l}\text { Claes, J.; Vanderfeesten, I.; Reijers, H.A.; Pinggera, J.; } \\
\text { Weidlich, M.; Zugal, S.; Fahland, D.; Weber, B.; Mendling, } \\
\text { J.; Poels, G. }\end{array}$ & 2012 & $\begin{array}{l}\text { Tying process model quality to the modeling process: the impact of } \\
\text { structuring, movement, and speed }\end{array}$ & $\begin{array}{l}\text { Business Process Management International Conference (BPM } \\
\text { 2012) }\end{array}$ \\
\hline Paper 51 & Yu, C.; Wu, G.; Yuan, M. & 2005 & Business process modeling based on workflow model reuse & $\begin{array}{l}\text { International Conference on Services Systems and Services } \\
\text { Management }\end{array}$ \\
\hline Paper 52 & $\begin{array}{l}\text { Rodrigues Nt, J.A.; de Souza, J.M.; Zimbrao, G.; Xexeo, G.; } \\
\text { Neves, E.; Pinheiro, W.A. }\end{array}$ & 2006 & A P2P approach for business process modelling and reuse & Business Process Management Workshops \\
\hline
\end{tabular}




\begin{tabular}{|c|c|c|c|c|}
\hline Number & Author & Year & Title & Source \\
\hline Paper 53 & Born, M.; Kirchner, J.; Mueller, J.P. & 2009 & Context-driven Business Process Modelling & $\begin{array}{l}\text { Joint Workshop on Advanced Technologies and techniques for } \\
\text { Enterprise Information Systems }\end{array}$ \\
\hline Paper 54 & Koschmider, A.; Song, M.; Reijers, H.A. & 2010 & Social software for business process modeling & Journal of Information Technology \\
\hline Paper 55 & Koschmider, A.; Hornung, T.; Oberweis, A. & 2011 & Recommendation-based editor for business process modeling & Data \& Knowledge Engineering \\
\hline Paper 56 & Holschke, O.; Rake, J.; Levina, O. & 2009 & $\begin{array}{l}\text { Granularity as a Cognitive Factor in the Effectiveness of Business } \\
\text { Process Model Reuse }\end{array}$ & $\begin{array}{l}\text { International Conference on Business Process Management } \\
\text { (BPM 2009) }\end{array}$ \\
\hline Paper 57 & Goncalves, J. C.de A.R.; Santoro, F.M.; Baiao, F. A. & 2011 & Let Me Tell You a Story - On How to Build Process Models & Journal of Universal Computer Science \\
\hline Paper 58 & Stolze, M. & 2008 & $\begin{array}{l}\text { Business process illustration: supporting experience-grounded } \\
\text { validation of new business processes by subject matter experts }\end{array}$ & IEEE Conference on E-Commerce Technology (CEC'08) \\
\hline Paper 59 & Rosemann, M. & 2006 & $\begin{array}{l}\text { Potential pitfalls of process modeling: part A.; Potential pitfalls of } \\
\text { process modeling: part B }\end{array}$ & Business Process Management Journal \\
\hline Paper 60 & Sánchez-González, L.; Ruiz, F.; García, F.; Piattini, M. & 2013 & Improving Quality of Business Process Models & $\begin{array}{l}\text { International Conference on Evaluation of Novel Approaches } \\
\text { to Software Engineering (ENASE 2011) }\end{array}$ \\
\hline Paper 61 & Thorn, L.H.; Reichert, M.; Chiao, C.M.; Iochpe, C.; Hess, G.N. & 2008 & $\begin{array}{l}\text { Inventing less, reusing more, and adding intelligence to business } \\
\text { process modeling }\end{array}$ & $\begin{array}{l}\text { Database and Expert Systems Applications International } \\
\text { Conference (DEXA 2008) }\end{array}$ \\
\hline Paper 62 & Soffer, P.; Kaner, M.; Wand, Y. & 2012 & $\begin{array}{l}\text { Towards Understanding the Process of Process Modeling: } \\
\text { Theoretical and Empirical Considerations }\end{array}$ & Business Process Management Workshops (BPM 2011) \\
\hline Paper 63 & Koschmider, A.; Song, M.; Reijers, H.A. & 2009 & $\begin{array}{l}\text { Advanced Social Features in a Recommendation System for Process } \\
\text { Modeling }\end{array}$ & International Conference on Business Information Systems \\
\hline Paper 64 & Tomaz, L.F.C.; Rodrigues Nt, J.A.; Xexéo, G.B.; Souza, J.M. & 2009 & Collaborative Process Modeling and Reuse Evaluation & $\begin{array}{l}\text { International Conference on Collaborative Computing: } \\
\text { Networking, Applications and Worksharing (CollaborateCom } \\
\text { 2009) }\end{array}$ \\
\hline Paper 65 & Ayad, S. & 2012 & $\begin{array}{l}\text { A quality based approach for the analysis and design of business } \\
\text { process models }\end{array}$ & $\begin{array}{l}\text { International Conference on Research Challenges in } \\
\text { Information Science (RCIS 2012) }\end{array}$ \\
\hline Paper 66 & Setiawan, M.A.; Sadiq, S. & 2013 & Integrated Framework for Business Process Complexity Analysis & European Conference on Information System (ECIS 2013) \\
\hline Paper 67 & Effinger, P.; Jogsch, N.; Seiz, S. & 2010 & $\begin{array}{l}\text { On a Study of Layout Aesthetics for Business Process Models Using } \\
\text { BPMN }\end{array}$ & $\begin{array}{l}\text { International Workshop on Business Process Modeling } \\
\text { Notation }\end{array}$ \\
\hline Paper 68 & Gruhn, V.; Laue, R. & 2009 & Reducing the Cognitive Complexity of Business Process Models & International Conference on Cognitive Informatics (ICCI'09) \\
\hline Paper 69 & Peters, N.; Weidlich, M. & 2009 & $\begin{array}{l}\text { Using Glossaries to Enhance the Label Quality in Business; Process } \\
\text { Models }\end{array}$ & $\begin{array}{l}\text { GI-Workshop Geschäftsprozessmanagement mit } \\
\text { Ereignisgesteuerten Prozessketten }\end{array}$ \\
\hline Paper 70 & $\begin{array}{l}\text { Nielen, A.; Koelter, D.; Muetze-Niewoehner, S.; Karla, J.; } \\
\text { Schlick, C.M. }\end{array}$ & 2011 & $\begin{array}{l}\text { An Empirical Analysis of Human Performance and Error in Process } \\
\text { Model Development }\end{array}$ & International Conference of Conceptual Modeling (ER 2011) \\
\hline Paper 71 & Rolón, E.; García, F.; Ruiz, F.; Piattini, M. & 2007 & $\begin{array}{l}\text { An Exploratory Experiment to Validate Measures for Business } \\
\text { Process Models }\end{array}$ & $\begin{array}{l}\text { International Conference on Research Challenges in } \\
\text { Information Science (RCIS 2007) }\end{array}$ \\
\hline Paper 72 & Renger, M.; Honig, J. & 2012 & $\begin{array}{l}\text { Improving the quality of business process models through } \\
\text { separation of generation tasks in collaborative modelling }\end{array}$ & $\begin{array}{l}\text { International Journal of Organisational Design and } \\
\text { Engineering }\end{array}$ \\
\hline
\end{tabular}




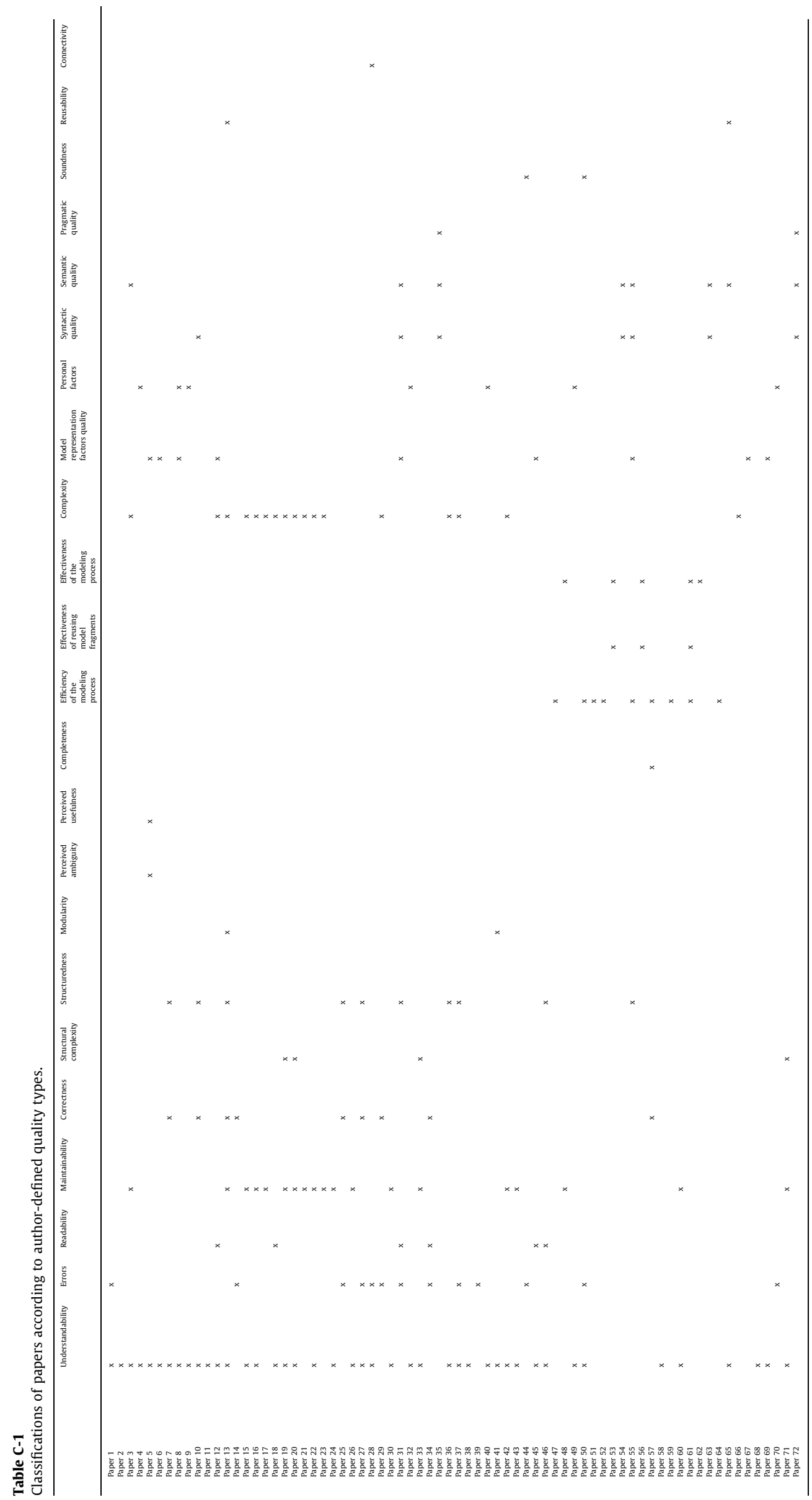




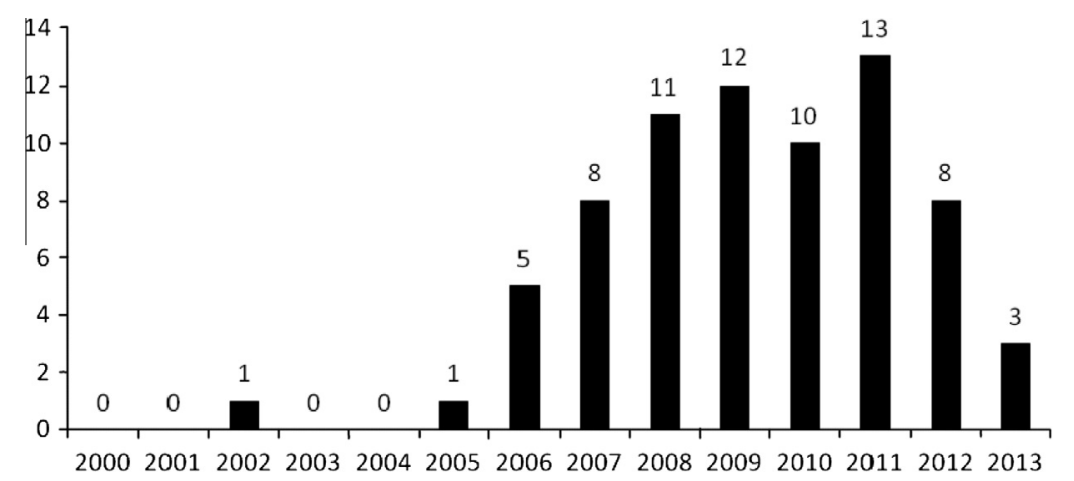

Fig. D-1. Number of publications per year.

Table D-1

Publications overview: business process modeling quality.

\begin{tabular}{|c|c|c|}
\hline Publication & Number & Percent \\
\hline Business Process Management International Conference & 8 & 11 \\
\hline Advanced Information Systems Engineering (CAiSE) International Conference & 5 & 7 \\
\hline Information and Software Technology Journal & 3 & 4 \\
\hline On the Move to Meaningful Internet Systems Conference & 3 & 4 \\
\hline Decision Support Systems Journal & 2 & 3 \\
\hline Information Systems Journal & 2 & 3 \\
\hline Data \& Knowledge Engineering Journal & 2 & 3 \\
\hline Business Information Systems Conference & 2 & 3 \\
\hline IEEE Transactions on Industrial Informatics Journal & 2 & 3 \\
\hline Conceptual Modeling Conference & 2 & 3 \\
\hline International Conference on Research Challenges in Information Science & 2 & 3 \\
\hline
\end{tabular}

Table D-2

Authors overview: business process modeling quality.

\begin{tabular}{lcc}
\hline Author & Number & Percent \\
\hline Jan Mendling & 28 & 39 \\
Hajo A. Reijers & 20 & 28 \\
Ralf Laue & 8 & 11 \\
Wil M.P. van der Aalst & 8 & 11 \\
Felix Garcia & 7 & 10 \\
Francisco Ruiz & 7 & 10 \\
Jorge Cardoso & 5 & 7 \\
Volker Gruhn & 5 & 7 \\
Jan Recker & 4 & 6 \\
Agnes Koschmider & 4 & 6 \\
Marcello La Rosa & 4 & 6 \\
Gustaf Neumann & 4 & 6 \\
Laura Sanchez-Gonzalez & 4 & 6 \\
Mario Piattini & 4 & 6 \\
\hline
\end{tabular}

\section{Appendix A. A brief introduction to the CMQF}

In the Conceptual Modeling Quality Framework, quality dimensions represent relations between two out of a set of eight cornerstones in total. These cornerstones are: physical domain, domain knowledge, physical model, model knowledge, physical language, language knowledge, physical representation and representation knowledge (for a complete explanation see [10]). On the one hand, these can be thought of as either sets of statements that constitute physical artifacts or represent cognitive artifacts used in or resulting from conceptual modeling (as in the SEQUAL framework). On the other hand, these can be thought of as sets of states of the conceptual modeling process (as in the BWW framework). Quality dimensions reflect relationships between these eight cornerstones. For example, semantic quality refers to the relationship between two physical cornerstones: (1) the set of statements formed by "the model" versus (2) the set of statements formed by "the physical domain".

The quality dimensions are grouped into four layers that follow the conceptual modeling process. These layers are the physical layer, knowledge layer, learning layer, and development layer. The physical layer has seven quality types, four of which relate to model quality ${ }^{1}$ : syntactic quality, semantic quality, intensional quality, and empirical quality. The knowledge layer represents relationships between cognitive cornerstones. It consists of seven quality types that parallel the physical layer quality types, four of which relate to model quality ${ }^{2}$ : perceived syntactic quality, perceived semantic quality, perceived intensional quality, and perceived empirical quality. Whereas the physical layer quality types are defined objectively, the corresponding knowledge layer quality types recognize a "subjective" notion of quality as perceived by the user or modeler. The learning layer measures how well learning, interpretation, and/or understanding takes place. It contains four quality types of which one refers to the model ${ }^{3}$ : pragmatic quality. Finally, the development layer presents the relationship between the physical layer and the knowledge layer in terms of developing artifacts, i.e. physical artifacts have their developmental roots in the knowledge layer artifacts. It has six quality types of which three relate to developing models ${ }^{4}$ : applied domain knowledge quality, applied model knowledge quality, and applied language knowledge quality.

\section{Appendix B. Papers in the final data set}

See Table B-1.

\section{Appendix C. Detailed results of data extraction}




\section{Appendix D. Demographic statistics}

Beyond the objective of this SLR which consists on determining the state of the art on business process modeling quality, this section provides some basic demographic statistics on business process modeling quality research.

As shown in Fig. D-1 there has been a progression in the number of publications on business process modeling quality between 2000 and 2013. A substantial increase on the research topic can be observed after 2006, reaching its highest point between 2008 and 2011. The decreasing in 2013 could be owed to the fact that at the time of writing this article some papers are still in the peer review or publication process.

If we focus on publication type we can see that $37 \%$ of the papers were published in Journals, $50 \%$ in Conference Proceedings and $13 \%$ in Workshop proceedings. Table D-1 shows the publication outlets with the largest amount of business process modeling quality papers. The first, the International Conference on Business Process Management includes conference proceedings and papers presented in the workshops.

Main authors in the business process modeling quality research area according to this SLR are shown in Table D-2.

\section{References}

[1] M. Born, J. Kirchner, J.P. Mueller, Context-driven business process modelling, in: O. Camp, S. Hammoudi (Eds.), Advanced Technologies and Techniques for Enterprise Information Systems (11th International Conference on Enterprise Information Systems (ICEIS 2009)), INSTICC Press, 2009, pp. 17-26.

[2] L. Sánchez-González, F. García, F. Ruiz, J. Mendling, Quality indicators for business process models from a gateway complexity perspective, Inf. Softw. Technol. 54 (2012) 1159-1174.

[3] D.L. Moody, Theoretical and practical issues in evaluating the quality of conceptual models: current state and future directions, Data Knowl. Eng. 55 (2005) 243-276

[4] J. Mendling, Empirical studies in process model verification, in: Transactions on Petri Nets and Other Models of Concurrency II, Special Issue on Concurrency in Process-Aware Information Systems, LNCS, 2009, pp. 208-224.

[5] J. Becker, M. Rosemann, C. von Uthmann, Guidelines of business process modeling, in: W. van der Aalst, J. Desel, A. Oberweis (Eds.), Business Process Management, Springer, Berlin/Heidelberg, 2000, pp. 241-262.

[6] J. Mendling, H.A. Reijers, W.M.P. van der Aalst, Seven process modeling guidelines (7PMG), Inf. Softw. Technol. 52 (2010) 127-136.

[7] O.I. Lindland, G. Sindre, A. Solvberg, Understanding quality in conceptual modeling, Softw. IEEE 11 (1994) 42-49.

[8] J. Krogstie, G. Sindre, H. Jørgensen, Process models representing knowledge fo action: a revised quality framework, Eur. J. Inform. Syst. 15 (2006) 91-102.

[9] H. Reijers, J. Mendling, J. Recker, Business process quality management, in: Handbook on Business Process Management, Springer, 2010, pp. 167-185.

[10] H.J. Nelson, G. Poels, M. Genero, M. Piattini, A conceptual modeling quality framework, Softw. Qual. J. 20 (2012) 201-228.

[11] D. Moody, G. Sindre, T. Brasethvik, A. Sølvberg, Evaluating the quality of process models: empirical testing of a quality framework conceptual modeling, in: S. Spaccapietra, S. March, Y. Kambayashi (Eds.), ER 2002, Springer, Berlin/Heidelberg, 2003, pp. 380-396.

[12] I.G. Arkilic, H.A. Reijers, R.R.H.M.J. Goverde, How good is an as-is model really?, in: M. Rosa, P. Soffer (Eds.), Business Process Management Workshops, Springer, Berlin Heidelberg, 2013, pp. 89-100.

[13] V. Gruhn, R. Laue, What business process modelers can learn from programmers, Sci. Comput. Program. 65 (2007) 4-13.

[14] M. La Rosa, A.H.M. ter Hofstede, P. Wohed, H.A. Reijers, J. Mendling, W.M.P. van der Aalst, Managing process model complexity via concrete syntax modifications, IEEE Trans. Industr. Inf. 7 (2011) 255-265.

[15] M. La Rosa, P. Wohed, J. Mendling, A.H.M. ter Hofstede, H.A. Reijers, W.M.P. van der Aalst, Managing process model complexity via abstract syntax modifications, IEEE Trans. Industr. Inf. 7 (2011) 614-629.

[16] J. Mendling, H.A. Reijers, J. Recker, Activity labeling in process modeling: empirical insights and recommendations, Inform. Syst. 35 (2010) 467-482.

[17] M. Rosemann, Potential pitfalls of process modeling: Part A, Bus. Process Manage. J. 12 (2006) 249-254.

[18] M. Rosemann, Potential pitfalls of process modeling: Part B, Bus. Process Manage. J. 12 (2006) 377-384.

[19] P. O'Neill, A.S. Sohal, Business process reengineering - a review of recent literature, Technovation 19 (1999) 571-581.
[20] S. Biazzo, Approaches to business process analysis: a review, Bus. Process Manage. J. 6 (2000) 99-112.

[21] R.S. Aguilar Saven, Business process modelling: review and framework, Int. J. Prod. Econ. 90 (2004) 129-149.

[22] M. Genero, A.M. Fernández-Saez, H.J. Nelson, G. Poels, M. Piattini, A systematic literature review on the quality of UML models, J. Database Manage. 22 (2011) 46-70.

[23] L. Aldin, S. de Cesare, A literature review on business process modelling: new frontiers of reusability, Enterprise Inform. Syst. 5 (2011) 359-383.

[24] L. Sanchez-Gonzalez, F. Garcia-Rubio, F. Ruiz-Gonzalez, M. Piattini-Velthuis, Measurement in business processes: a systematic review, Bus. Process Manage. J. 16 (2010) 114-134.

[25] J. Mendling, Metrics for Process Models: Empirical Foundations of Verification, Error Prediction, and Guidelines for Correctness, Springer-Verlag, Berlin Heidelberg, 2008.

[26] B. Kitchenham, S. Charters, Guidelines for performing systematic literature reviews in software engineering, in: Keele University and Durham University Joint Report, 2007, pp. 6-30.

[27] F.Q.B. da Silva, Six years of systematic literature reviews in software engineering: an updated tertiary study, Inf. Softw. Technol. 53 (2011) 899-913.

[28] S.T. March, G.F. Smith, Design and natural science research on information technology, Decis. Support Syst. 15 (1995) 251-266.

[29] H. Zhang, M. Ali-Babar, P. Tell, Identifying relevant studies in software engineering, Inf. Softw. Technol. 53 (2011) 625-637.

[30] P. Brereton, B.A. Kitchenham, D. Budgen, M. Turner, M. Khalil, Lessons from applying the systematic literature review process within the software engineering domain, J. Syst. Softw. 80 (2007) 571-583.

[31] J. Mendling, J. Recker, Towards systematic usage of labels and icons in business process models, in: T. Halpin, E. Proper, J. Krogstie, X. Franch, E. Hunt, R. Coletta (Eds.), 13th International Workshop on Exploring Modeling Methods for Systems Analysis and Design (EMMSAD’08) Montpellier, France, 2008, pp. $1-13$.

[32] L. Sánchez-González, F. García, J. Mendling, F. Ruiz, M. Piattini, Prediction of business process model quality based on structural metrics, in: J. Parsons, M. Saeki, P. Shoval, C. Woo, Y. Wand (Eds.), ER 2010, Springer-Verlag, Berlin Heidelberg, 2010, pp. 458-463.

[33] B. Kitchenham, P. Brereton, A systematic review of systematic review process research in software engineering, Inf. Softw. Technol. 55 (2013) 2049-2075.

[34] M. Dumas, M.L. Rosa, J. Mendling, H.A. Reijers, Fundamentals of Business Process Management, Springer-Verlag, Berlin Heidelberg, 2013.

[35] ISO, ISO Standard 9000-2000, Quality management systems: fundamentals and vocabulary, in: International Standards Organisation (ISO), 2000.

[36] Y. Wand, R. Weber, An ontological model of an information system, IEEE Trans. Software Eng. 16 (1990) 1282-1292.

[37] A.R. Hevner, S.T. March, J. Park, S. Ram, Design science in information systems research, MIS Quart. 28 (2004) 75-105.

[38] R. Wille, Formal concept analysis as mathematical theory of concepts and concept hierarchies, in: Formal Concept Analysis, 2005, pp. 1-33.

[39] B. Weber, M. Reichert, J. Mendling, H.A. Reijers, Refactoring large process model repositories, Comput. Ind. 62 (2011) 467-486.

[40] J. Mendling, H.M.W. Verbeek, B.F. van Dongen, W.M.P. van der Aalst, G. Neumann, Detection and prediction of errors in EPCs of the SAP reference model, Data Knowl. Eng. 64 (2008) 312-329.

[41] J. Mendling, H.A. Reijers, J. Cardoso, What makes process models understandable?, in: G. Alonso, P. Dadam, M. Rosemann (Eds.), Business Process Management, Springer-Verlag, Berlin Heidelberg, Brisbane, Australia, 2007, pp. 48-63.

[42] J. Mendling, G. Neumann, Error metrics for business process models, in: International Conference on Advanced Information Systems Engineering, 2007.

[43] J. Mendling, L. Sánchez-González, F. García, M. La Rosa, Thresholds for error probability measures of business process models, J. Syst. Softw. 85 (2012) 1188-1197.

[44] H.A. Reijers, J. Mendling, R.M. Dijkman, Human and automatic modularizations of process models to enhance their comprehension, Inform. Syst. 36 (2011) $881-897$.

[45] J. Mendling, J. Recker, H.A. Reijers, On the usage of labels and icons in business process modeling, Int. J. Inform. Syst. Model. Des. 1 (2010) 40-58.

[46] G. Reggio, M. Leotta, F. Ricca, "Precise is better than light" a document analysis study about quality of business process models, in: 2011 First International Workshop on Empirical Requirements Engineering, 2011, pp. 61-68.

[47] M. Schrepfer, J. Wolf, J. Mendling, H.A. Reijers, The impact of secondary notation on process model understanding, in: A. Persson, J. Stirna (Eds.), The Practice of Enterprise Modeling, 2nd IFIP WG8.1 Working Conference (PoEM 2009), IFIP International Federation for Information Processing, Stockholm, Sweden, 2009, pp. 161-175.

[48] H.A. Reijers, T. Freytag, J. Mendling, A. Eckleder, Syntax highlighting in business process models, Decis. Support Syst. 51 (2011) 339-349.

[49] ISO/IEC, Software Engineering - Product Quality - Part 1: Quality Model, 2001.

[50] K.D. Schenk, N.P. Vitalari, K. Shannon Davis, Differences between novice and expert systems analysts: what do we know and what do we do?, J Manage. Inform. Syst. 15 (1998) 9-50. 